OPEN ACCESS

Edited by: Nahid Ali, Indian Institute of Chemical Biology, India

Reviewed by: Owen Kavanagh, York St John University, UK

Leonardo Freire-de-Lima, Federal University of Rio de Janeiro,

Brazil

*Correspondence: Clarisa B. Palatnik-de-Sousa immgcpa@micro.ufrj.br

Specialty section: This article was submitted to Vaccines and Molecular Therapeutics, a section of the journal Frontiers in Immunology

Received: 18 November 2016 Accepted: 20 January 2017 Published: 23 February 2017

Citation: Alves-Silva MV, Nico D, Morrot A, Palatnik $M$ and Palatnik-de-Sousa $C B$ (2017) A Chimera Containing CD4+ and CD8+ T-Cell Epitopes of the Leishmania donovani Nucleoside

Hydrolase (NH36) Optimizes Cross-Protection against Leishmania amazonesis Infection.

Front. Immunol. 8:100. doi: 10.3389/fimmu.2017.00100

\section{A Chimera Containing CD4+ and CD8+ T-Cell Epitopes of the Leishmania donovani Nucleoside Hydrolase (NH36) Optimizes Cross-Protection against Leishmania amazonesis Infection}

\author{
Marcus Vinícius Alves-Silva ${ }^{1,2}$, Dirlei Nico', Alexandre Morrot ${ }^{3}$, Marcos Palatnik $^{4}$ and \\ Clarisa B. Palatnik-de-Sousa ${ }^{1,5 *}$
}

'Laboratório de Biologia e Bioquímica de Leishmania, Departamento de Microbiologia Geral, Instituto de Microbiologia Paulo de Góes, Universidade Federal do Rio de Janeiro, Rio de Janeiro, Rio de Janeiro, Brazil, ${ }^{2}$ Programa de PósGraduação em Biotecnologia Vegetal e Bioprocessos, Centro de Ciências da Saúde, Universidade Federal do Rio de Janeiro, Rio de Janeiro, Rio de Janeiro, Brazil, ${ }^{3}$ Laboratório de Imunologia Integrada, Departamento de Imunologia, Instituto de Microbiologia Paulo de Góes, Universidade Federal do Rio de Janeiro, Rio de Janeiro, Rio de Janeiro, Brazil, ${ }^{4}$ Programa de Pós-Graduação em Clínica Médica, Faculdade de Medicina-Hospital Universitario Clementino Fraga Filho, Universidade Federal do Rio de Janeiro, Rio de Janeiro, Rio de Janeiro, Brazil, ${ }^{5}$ Faculdade de Medicina, Instituto de Investigação em Imunologia, Universidade de São Paulo (USP), São Paulo, São Paulo, Brazil

The Leishmania donovani nucleoside hydrolase (NH36) and $\mathrm{NH}$ A34480 of Leishmania amazonensis share $93 \%$ of sequence identity. In mice, the NH36 induced protection against visceral leishmaniasis is mediated by a CD4+ $T$ cell response against its C-terminal domain (F3). Besides this CD4+ Th1 response, prevention and cure of $L$. amazonensis infection require also additional CD8+ and regulatory T-cell responses to the NH36 N-terminal (F1 domain). We investigated if mice vaccination with $\mathrm{F} 1$ and F3 domains cloned in tandem, in a recombinant chimera, with saponin, optimizes the vaccine efficacy against $L$. amazonensis infection above the levels promoted by the two admixed domains or by each domain independently. The chimera induced the highest IgA, IgG, and IgG2a anti-NH36 antibody, IDR, IFN- $\gamma$, and IL-10 responses, while TNF- $\alpha$ was more secreted by mice vaccinated with F3 or all F3-contaning vaccines. Additionally, the chimera and the $F 1$ vaccine also induced the highest proportions of CD4+ and CD8+ T cells secreting IL-2, TNF- $\alpha$, or IFN- $\gamma$ alone, TNF- $\alpha$ in combination with IL- 2 or IFN- $\gamma$, and of CD4+ multifunctional cells secreting IL-2, TNF- $\alpha$, and IFN- $\gamma$. Correlating with the immunological results, the strongest reductions of skin lesions sizes were determined by the admixed domains (80\%) and by the chimera (84\%), which also promoted the most pronounced and significant reduction of the parasite load (99.8\%). Thus, the epitope presentation in a recombinant chimera optimizes immunogenicity and efficacy above the levels induced by the independent or admixed F1 and F3 domains. The multiparameter analysis disclosed that the Th1-CD4+ Thelper response induced by the chimera is mainly directed against its FRYPRPKHCHTQVA epitope. Additionally, the YPPEFKTKL epitope of $\mathrm{F} 1$ induced the second most important CD4+ T cell response, and, followed by the 
DVAGIVGVPVAAGCT, FMLQILDFYTKVYE, and ELLAITTVVGNQ sequences, also the most potent CD8+ T cell responses and IL-10 secretion. Remarkably, the YPPEFKTKL epitope shows high amino acid identity with a multipotent PADRE sequence and stimulates simultaneously the CD4+, CD8+ $T$ cell, and a probable $T$ regulatory response. With this approach, we advanced in the design of a NH36 polytope vaccine capable of inducing cross-protection to cutaneous leishmaniasis.

Keywords: nucleoside hydrolases, T-cell epitope vaccines, visceral and cutaneous leishmaniasis, Leishmania amazonensis, PADRE epitopes

\section{INTRODUCTION}

Leishmaniasis is a complex of protozoan vector-borne diseases of recent increased worldwide incidence (1). Clinical manifestations of the disease range from visceral leishmaniasis (VL), the most severe and fatal syndrome with 400,000 new cases/ year, characterized by a strong suppression of the CD4+ T-cell response, to tegumentary leishmaniasis, with 7 to 1.2 million new annual cases and variable degrees of T-cell immunity (2). Clinical cases of cutaneous leishmaniasis (CL), the most benign form of tegumentary leishmaniasis, show skin ulcers and a $\mathrm{T}$ cell-mediated active immune response, which is often responsible of self-healing or worsening of the disease (2). Mucocutaneous leishmaniasis (MCL), on the other hand, involves an exacerbated immune inflammatory response and lesions of cutaneous and mucosal tissues, while diffuse cutaneous leishmaniasis (DCL), the anergic form of disease, is associated to high Leishmania-specific inhibition of the T-cell responses (3). A few patients also develop the borderline disseminated leishmaniasis (4).

Afghanistan, Algeria, Colombia, Brazil, Iran, Syria, Ethiopia, North Sudan, Costa Rica, and Peru are the 10 countries with higher incidence of CL, and together they account for 70-75\% of the estimated global occurrence (2). Regarding the ethyological agents of tegumentary leishmaniasis, Leishmania amazonensis is a causative agent of CL, MCL, and DCL in Northern, South America, and Brazil (3-7).

Chemotherapy of leishmaniasis is highly toxic, and many cases of resistance or recurrent disease were reported (8-10). Alternatively, vaccine-mediated prevention or cure of CL was assayed with first generation formulations since the $80 \mathrm{~s}$, achieving, however, no more than $50 \%$ efficacy $(8,11)$. Only one vaccine based on L. amazonensis lysate is licensed at present for immunochemotherapy in Brazil (8).

Since three licensed vaccines against canine VL are available at present (12-14), one feasible approach to induce cross-protection against CL would be to use the vaccine antigens that are conserved in the Leishmania genus $(15,16)$ and already demonstrated to confer protection against VL $(12,17-19)$, the most immunosuppressive and severe form of the disease.

The Leishmania donovani nucleoside hydrolase (NH36) (17) is the main antigen of the Leishmune ${ }^{\circledR}$ vaccine, the first licensed veterinary vaccine against canine $\operatorname{VL}(12,18)$. Leishmune ${ }^{\circledR}$ shows $76-80 \%$ vaccine efficacy $(18,19)$, and its use in endemic areas already promoted the decrease of the canine and the human incidence of VL (12).
Nucleoside hydrolases are enzymes of the DNA metabolism of bacteria, fungi, and protozoa which release exogenous purines or pyrimidines from nucleosides, in microorganisms that are not able to synthetize them, enabling in this way an efficient pathogen replication. They are absent in mammals $(20,21)$.

Vaccination with the $\mathrm{NH}$ of $L$. donovani, NH36, in its native form, protected mice against $L$. donovani infection (22), and in its DNA or recombinant protein forms induced efficacy against mice $(17,23,24)$ and dog infections by Leishmania chagasi (25), and against mice challenged with Leishmania mexicana (23), Leishmania major (26), and L. amazonensis (27-29), the respective agents of cutaneous and diffuse leishmaniasis. NHs are considered strong phylogenetic markers of the genus Leishmania $(15,16)$, and their amino acid sequences are strongly conserved $(29,30)$. In fact, the sequence of $L$. donovani $\mathrm{NH} 36$ is homologous to the NH sequences of all the studied species of Leishmania: $L$. major (95\%) (31), L. chagasi (99\%), Leishmania infantum (99\%), L. amazonensis (93\%) (28), L. mexicana (93\%), Leishmania braziliensis (84\%), and Leishmania tropica (97\%) (32).

Therefore, NH36 becomes a good candidate for the development of a cross-protective and universal vaccine against leishmaniasis. Using recombinant generated proteins covering the whole sequence of NH36, and saponin, in previous work, we demonstrated that protection against mice $\mathrm{VL}$ is mediated by a CD4+ T cell response against epitopes of the NH36 C-terminal domain (F3) (17). On the other hand, prevention (28) and cure of mice CL (29) caused by L. amazonensis are determined by a CD4+-Th1 cell-mediated response toward the F3 protein and a $\mathrm{CD} 8+$ and regulatory $\mathrm{T}$-cell responses directed to the $\mathrm{N}$-terminal (F1) domain of NH36, which promoted simultaneous increased secretions of IFN- $\gamma$, TNF- $\alpha$, and IL-10 (29).

Additionally, the $\mathrm{F} 3$ vaccine promoted in mice a 36 and $40 \%$ respective higher average protection than those generated by the NH36-vaccine against VL, induced by L. chagasi (17), and CL, caused by L. amazonensis (28). These results confirmed that the use of the domain containing the relevant epitopes enhances the efficacy over that induced by the cognate whole protein (33).

Multisubunit vaccines against leishmanial infection have been shown to be more promising (34). Additionally, the most efficient protection is considered to be determined by diverse $\mathrm{T}$ cells that respond to a group of the pathogen-derived epitopes (35). Recent research in immunity to leishmaniasis disclosed the importance of multifunctional CD4+ and CD8+ T cells in the generation of a Th1 response to control infection $(34,36,37)$. According to that, it has been suggested that the in silico tools should be used to 
search in the Leishmania genome for potential candidates with both CD4+ and CD8+ T cell-stimulating competences. Epitope mapping could then be used to design a polyepitope vaccine that could carry conserved epitopes, which bind to many HLA or MHC allotypes, or which are present in many species of a Leishmania genus (34).

Although the whole NH36 protein would be easier to work with, it would be also much less potent. In fact, according to the philosophy of the development of T-epitope vaccines, the whole cognate protein is less potent than the domains that contain the important epitopes. The domains are also more immunogenic than the isolated epitopes. Our aim, in this investigation, was to increase potency and optimize the vaccine. In agreement to that, we were able to show that a combination of these domains in a chimera even enhances the protective efficacy demonstrated for each domain independently. Our results support that the use of the domain containing the relevant epitopes enhances the vaccine efficacy over that induced by the cognate whole protein (33).

In fact, we evaluated if the administration of F1 and F3 domains of NH36 expressed in tandem, as a recombinant chimera, optimizes the immunogenicity and vaccine efficacy against mice infection by L. amazonensis, above the levels promoted by the two admixed domains and by each protein administered alone. We additionally identified the most important epitopes of F1 and F3 responsible for the generation of the cellular immune response. In this investigation, we aimed to progress in the development of a universal NH36 T-cell epitope vaccine capable of protecting against the infection by L. amazonensis.

\section{MATERIALS AND METHODS}

\section{Ethical Statement}

This study was carried out in accordance with the recommendations of National Institutes of Health, USA. The protocol was approved by the Comissão de Avaliação da Utilização de Animais em Pesquisa do Centro de Ciência da Saúde (CEUA), Universidad Federal do Rio de Janeiro (CONCEA, Brazil, 01200.001568/201387, IMPPG-016).

\section{Recombinant Antigens Expression and Purification and Epitopes}

NH36 is composed of 314 amino acids (Genbank access number AY007193, SwissProt-UniProtaccess number Q8WQX2-LEIDO). The N-terminal (F1, amino acid sequences 1-103), the central (F2, amino acids 104-198), and the C-terminal (F3, amino acids 199-314) domains were cloned in the pET28 plasmid system, between the restriction sites of $\mathrm{NcoI}$ and $\mathrm{XhoI}$ (17). Furthermore, the F1F3 recombinant chimera containing the sequence of the F1 followed by the F3 protein, cloned between the restriction sites of NcoI and XhoI was obtained with optimized codons in the PET28b expression vector by GenScript (NJ, USA). All the recombinant proteins used in this investigation were expressed with a six His-Tag at their C-terminals.

For protein expression, pET28bNH36, pET28bF1, pET28bF3, or pET28bF1F3-transformed E. coli BI21DE3 bacteria were amplified into 21 of LB culture medium with kanamycin.
Expression was induced with $1 \mathrm{mM}$ IPTG (isopropyl-betaD-thiogalactopyranoside-Fermentas) for $4 \mathrm{~h}$ at $37^{\circ} \mathrm{C}$, and cultures were centrifuged. The pellets were sonicated and further centrifuged for $20 \mathrm{~min}$ under $14,000 \mathrm{rpm}$ at $4^{\circ} \mathrm{C}$. The recombinant proteins were more concentrated in the pellets, which were purified by affinity column chromatography with Ni-NTA resin according to the manufacturer's instructions (Qiagen). Briefly, each pellet was incubated with $10-15 \mathrm{ml}$ urea buffer ( $8 \mathrm{M}$ urea, $1 \mathrm{M} \mathrm{Na}_{2} \mathrm{HPO}_{4}, 1 \mathrm{M} \mathrm{NaH}_{2} \mathrm{PO}_{4}$, and $1 \mathrm{M}$ Tris-HCl) pH 8.0, for $2 \mathrm{~h}$, on ice. Then, the suspension was homogenized by successive passages through $20 \mathrm{ml}$ syringes with $1.2 \mathrm{~mm} \times 40 \mathrm{~mm}$ needles, until complete dissolution and centrifuged for $15 \mathrm{~min}$ at $14,000 \mathrm{rpm}$ at $4^{\circ} \mathrm{C}$. The supernatants containing the solubilized proteins were loaded on the Ni-NTA column previously equilibrated with urea buffer. Then, the column was washed with 5 volumes of urea buffer, $\mathrm{pH}$ 8.0, for removal of non-specifically bound proteins and with additional 5 volumes of urea buffer, $\mathrm{pH}$ 6.4-6.5, for removal of bacterial proteins containing His residues. The recombinant antigens were recovered in 10 volumes of urea buffer $\mathrm{pH} 4.5$, dialyzed overnight against $\mathrm{PBS}$ at $4^{\circ} \mathrm{C}$, and preserved with $1 \mathrm{mM}$ PMSF and $5 \%$ glycerol at $-80^{\circ} \mathrm{C}(17)$. The absence of LPS was confirmed using the LAL QCL-1000 kit (Lonza).

Furthermore, CD4+ T cell epitopes predicted by the Protean Pad program based on the A. Sette algorithm for the $\mathrm{H} 2{ }^{\mathrm{d}}$ haplotype of Balb/c mice (IA ${ }^{\mathrm{d}}$ and $\mathrm{IE}^{\mathrm{d}}$ alleles) (17) and the CD8+ T cell epitopes ( $\mathrm{H} 2 \mathrm{~L}^{\mathrm{d}}$ haplotype), identified by the HLA peptide motif search $^{1}$ and the SYFPEITHI ${ }^{2}$ programs (17) were synthetized by GenScript (NJ, USA). A model of the structure of the NH36 monomer and of the spatial distribution of the predicted epitopes in F1 and F3 is represented in Figure S1 in Supplementary Material.

\section{Vaccine Efficacy Assay}

Groups of BALB/c females (2-month old) were randomized by corporal weight and immunized with three subcutaneous doses of each respective vaccine: F1 $(100 \mu \mathrm{g}), \mathrm{F} 3(100 \mu \mathrm{g}), \mathrm{F} 1(50 \mu \mathrm{g})$, and F3 $(50 \mu \mathrm{g})$ administered as a simple mixture $(\mathrm{F} 1+\mathrm{F} 3)$, and F1F3 chimera (100 or $200 \mu \mathrm{g}$ ). All antigens were formulated with $100 \mu \mathrm{g}$ of Riedel de Haen saponin (Sigma, St. Louis, MO, USA) in $0.2 \mathrm{ml}$ of $0.9 \% \mathrm{NaCl}$ saline solution and injected subcutaneously in the back, at weekly intervals $(17,28,29)$. Control animals received only saline. Mice were infected subcutaneously in the right hind footpads with $10^{6}$ stationary phase infective promastigotes of L. amazonensis IFLA/BR/67/PH8, 10 days after the last vaccine dose. Briefly, infective parasites were obtained from hamsters footpads in $10 \%$ fetal calf serum, $50 \mathrm{U}$ penicillin, and $50 \mu \mathrm{g}$ streptomycin/ml (Cultilab, Brazil) supplemented Schneider's Drosophila medium (Sigma). Parasites where then cultured using a $1 / 5$ serial dilution, in 24 -well plates, at $26^{\circ} \mathrm{C}$, during 3 days. On day 4, $400 \mu \mathrm{l}$ of promastigote suspensions was amplified through three successive passages in Schneider's supplemented medium and finally, the stationary-phase parasites

${ }^{1}$ http://bimas.dcrt.nih.gov/molbio/hla_bind/

${ }^{2}$ http://www.syfpeithi.de/ 
were centrifuged, washed twice, suspended in saline solution, counted in a hemocytometer, and used for infection.

The evolution of lesion sizes in footpads was monitored weekly, with a Mitutoyo ${ }^{\circledR}$ pachymeter. Measures of the infected footpads were subtracted from the contra-lateral controls injected only with saline.

At week 12, mice were euthanized with $\mathrm{CO}_{2}$ and their parasite load determined by a limiting dilution assay. Briefly, the infected paws were removed under aseptic conditions and washed with Schneider's medium. Fragments of bones, nails, and skin were chirurgically removed. The remaining tissue was chopped into small pieces and suspended into $1 \mathrm{ml}$ supplemented Schneider's medium. A $1 / 5$ serial dilution of this suspension was obtained in a 24 -well plate that was further incubated at $26^{\circ} \mathrm{C}$ for 4 days, with daily observation in an inverted microscope. The number of promastigotes present at the last well containing visible parasites was quantified in a hemocytometer.

The anti-NH36 antibody response was assessed in sera, and the intradermal response to leishmanial antigen, and the secretion and intracellular expression of cytokines by antigen-stimulated CD4 and CD8 lymphocytes were studied 1 week after complete vaccination and on week 12 after infection.

\section{Antibody Assay in Sera}

Anti-NH36 antibodies were assayed in the sera of mice, using a standard ELISA assay. Plates were treated with $2 \mu \mathrm{g}$ NH36 per well in carbonate-bicarbonate buffer $\mathrm{pH} 9.6$, washed with $0.018 \mathrm{M}$ PBS, pH 7.2, 1\% non-fat milk, and $0.05 \%$ Tween-20 buffer $\left(\mathrm{PBS}^{*}\right)$, and further incubated with diluted sera samples in $\mathrm{PBS}^{*}$ for $1 \mathrm{~h}$ at $37^{\circ} \mathrm{C}$. Then, plates were washed and treated with peroxidaseconjugated goat anti-mouse-IgA, IgM, IgG1, or IgG2a antibodies $(1: 4,000)$ (Southern Biotechnology Associates, Birmingham, AL, USA) or with protein-A-peroxidase (Kirkegaard \& Perry Laboratories, Gaithersburg, MD, USA, EEUU) at 1:1,000 dilution in $\mathrm{PBS}^{*}$. Reaction was developed with ortho-phenylenediamine buffer (Sigma), interrupted with $1 \mathrm{~N}$ sulfuric acid, and monitored at $492 \mathrm{~nm}$. Results were expressed as the mean of absorbance values of 1/100 diluted sera of each animal, in triplicates, in double-blind tests.

\section{Intradermal Skin Test (IDR)}

Mice were injected in their right front footpad with $0.1 \mathrm{ml}$ $0.9 \% \mathrm{NaCl}$ saline solution containing the lysate of $10^{7}$ freezethawed stationary-phase L. amazonensis infective promastigotes obtained as described in Section "Vaccine Efficacy Assay." The footpad swallow was monitored with a Mitutoyo apparatus, both before and at 0,24 , and $48 \mathrm{~h}$ after lysate injection. Each measure was subtracted from the values of the left front footpads injected with only saline (28).

\section{Secreted Cytokines Assay}

Spleens were excised, and single-cell suspensions were prepared in $1 \mathrm{ml}$ RPMI medium (Sigma, Co) supplemented with $10 \%$ fetal calf serum (Nutricell, Campinas, São Paulo, Brazil), $1 \%$ L-glutamine, and $5 \mathrm{mM} 2$ - $\beta$-mercaptoethanol. Then, cells were counted in a hemocytometer, distributed into a 96-well plate $\left(10^{6} /\right.$ well), and incubated with $5 \mu \mathrm{g} /$ well $\mathrm{NH} 36$, or with no addition, for $72 \mathrm{~h}$ in vitro, at $37^{\circ} \mathrm{C}$ with $5 \%$ of $\mathrm{CO}_{2}$. Culture supernatants were collected and assayed for IFN- $\gamma$, TNF- $\alpha$, and IL-10 using the OptEIA mouse ELISA Set II kits (Becton and Dickinson, BD-Biosciences, USA) according to the manufacturer's instructions. The sensitivity of the assay was established with a range of $0-1,000 \mathrm{pg} / \mathrm{ml}$ for TNF- $\alpha$ and IL-10 and of $0-200 \mathrm{pg} / \mathrm{ml}$ for IFN- $\gamma$. Reactions were developed using biotinylated anti-cytokine antibodies, streptavidin (SAv-HRP) enzymatic reagent, and TMB (Zymed, USA). Absorbances were monitored at $655 \mathrm{~nm}$.

\section{Intracellular Cytokine Staining (ICS) and Flow Cytometry}

Splenocytes suspended in RPMI medium were distributed into 96-well Costar plates $\left(10^{6} /\right.$ well $)$ and stimulated with $25 \mu \mathrm{g} / \mathrm{ml}$ recombinant $\mathrm{NH} 36$ or with no addition, for $24 \mathrm{~h}$ at $37^{\circ} \mathrm{C}$ with $5 \% \mathrm{CO}_{2}$ according to the results of previous experiments. The intracellular expression of IL-2, TNF- $\alpha$, and IFN- $\gamma$ by CD $4+$ and CD8+ T cells was determined by multiparameter analysis $(36,37)$ after incubation with $10 \mu \mathrm{g} / \mathrm{ml}$ brefeldin (Sigma) for $4 \mathrm{~h}$ at $37^{\circ} \mathrm{C}$, $5 \% \mathrm{CO}_{2}$. After washing with FACS buffer (PBS containing 2\% bovine fetal calf, $0.1 \%$ sodium azide), splenocytes were labeled for $20 \mathrm{~min}$ at $4^{\circ} \mathrm{C}$, in the dark with rat anti-mouse-CD4FITC (clone GK1.5) and -CD8FITC (clone 53-6.7) monoclonal antibodies (R\&D systems, Inc.). Cells were then fixed with $4 \%$ para-formaldehyde, washed and treated with FACS buffer containing $0.5 \%$ saponin (Sigma), and further stained with IFN$\gamma$ APC, IL-2-PerCP-Cy5.5, and TNF- $\alpha$ PE monoclonal antibodies (BD-Pharmingen). For ICS, gating for CD4+ ad CD8+ T cells was performed, and 100,000 events were acquired in a Becton Dickinson FACScalibur. Data were analyzed using the FlowJo program (Tree Star, USA).

\section{Epitope Assays}

Splenocytes of mice vaccinated with the chimera $(100 \mu \mathrm{g} / \mathrm{dose})$ or saline solution and further challenged with $10^{6}$ promastigotes of L. amazonensis were incubated in vitro with $25 \mu \mathrm{g} / \mathrm{ml}$ of NH36, F1F3 chimera, each one of the CD4 predicted epitopes of F1 (ELLAITTVVGNQ and DVAGIVGVPVAAGCT) and F3 domains (FMLQILDFYTKVYE, FRYPRPKHCCHTQVA, and KFWCLVIDALKRIG), with the highest scored CD8 predicted epitope of the F1 protein (YPPEKTKL), or with the mixture of all the epitopes, at week 11 after infection. The epitope-specific cellular immune response was studied through the analysis of the cytokine secretion to supernatants and by multiparameter cytometry, as described above.

\section{Statistical Methods}

Means were compared by the Kruskal-Wallis and MannWhitney methods. Spearman's two-tailed correlation test was used for correlation analysis. Furthermore, the slope of the curves of variation of lesion sizes along the time was calculated as the best-fit values (GraphPad Prism6 software). All experiments were performed at least twice, and the indicated error bars are based on the SE. 


\section{RESULTS}

\section{The F1F3 Chimera Optimizes the Antibody Response}

We investigated, for all variables, if the vaccine containing the mixture of the F1 and F3 domains $(\mathrm{F} 1+\mathrm{F} 3)$ was more potent than the F1 and F3 vaccines independently. Our strategy also involved the use of the chimera at the dosage of $100 \mu \mathrm{g}$, in order to make a fair comparison with the simple addition of the two domains $(\mathrm{F} 1+\mathrm{F} 3)$, since both vaccines are composed of approximately $50 \mu \mathrm{g}$ of each F1 and F3 proteins. Additionally, we also used the chimera at the dosage of $200 \mu \mathrm{g}$, to disclose any potential doseresponse effect of increased efficacy determined by a higher dose of the antigen.

Initially, we compared the antibody response generated by the vaccines, both after complete immunization and after challenge by L. amazonensis (Figures 1 and 2). In contrast to what observed for the IgM antibodies (Figures 1C,D), the F1 protein alone did not induce any anti-NH36 antibodies of the IgG class or subclasses. The F3 vaccine on the other hand enhanced the IgM and all IgG antibodies against NH36 above the saline controls ( $p<0.0001$ for all comparisons) (Figures 1C,D and 2A-F). The IgM antibodies were equally enhanced by the F3 and the chimera vaccines before challenge and by the $\mathrm{F} 3$ vaccine after challenge (Figure 1).
Furthermore, the admixed domains induced more IgG, IgG1, and IgG2a antibodies than the F3 or the F1 vaccines did independently ( $p<0.007$ for both) indicating that the administration of both proteins simultaneously potentiates the effect (Figures 1A,B and 2).

Remarkably, the chimera vaccine optimized the antibody response by inducing the highest IgA, IgG, and IgG2a anti-NH36 responses (Figures $\mathbf{1 A}, \mathbf{B}$ and $\mathbf{2 A}-\mathbf{C}, \mathbf{E}, \mathbf{F}$ ). In fact, the dose of $200 \mu \mathrm{g}$ determined additional increases of $19 \%$, in the absorbency values, above those of the F1 + F3 and chimera ( $100 \mu \mathrm{g})$ vaccines ( $p<0.0001$ for both) revealing maximal optimization of the IgG response (Figure 2A). The $200 \mu \mathrm{g}$ F1F3 chimera was also the strongest formulation for the IgG class after challenge $(p<0.0148$ for all comparisons) (Figure 2B) while the admixed proteins $(\mathrm{F} 1+\mathrm{F} 3)$ were no longer superior to the $\mathrm{F} 3$ vaccine.

Noteworthy and in agreement with what described for the IgG response, after immunization, the chimeras induced the most potent and optimized IgG2a response (Figure 2E). The dosage of $100 \mu \mathrm{g}$ exhibited an increase of $20 \%(p<0.0001)$ in the IgG2a antibody titers, above the $\mathrm{F} 1+\mathrm{F} 3$ vaccine, indicating that the presentation of the epitopes in tandem increases the efficacy. Additionally, and similar to what described for IgG (Figure 1A), the maximal IgG2a antibody response was induced by the $200 \mu \mathrm{g}$ chimera vaccine, which promoted a $19 \%$ higher IgG2a response than the same vaccine at $100 \mu \mathrm{g}$ dosage $(p<0.0001)$, indicating

\section{after immunization}

\section{after challenge}
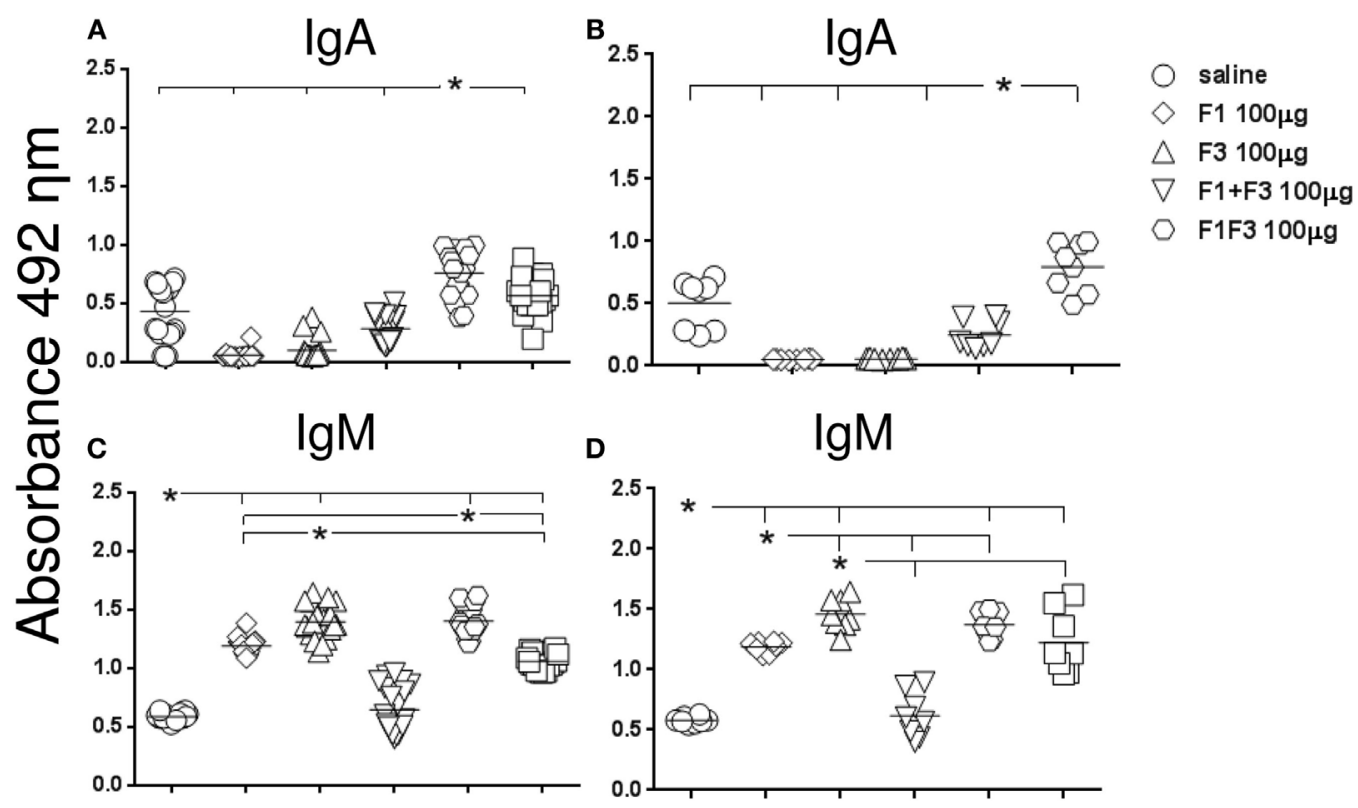

FIGURE 1 | Chimera enhances the IgA and, together with F3, the IgM anti-NH36 antibody response. BALB/c mice were immunized with three

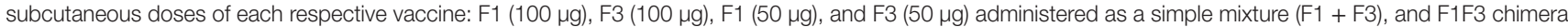
(100 or $200 \mu \mathrm{g}$ ), all formulated in $100 \mu \mathrm{g}$ of saponin. Anti-NH36 antibodies were measured by an ELISA assay in the sera of mice after vaccination (A,C) and on week 12 after infection with Leishmania amazonensis (B,D). Data are means and individual results of two independent experiments, each one with 8-10 animals per treatment. The chimera vaccine induced the highest IgA response (A,B). The IgM antibodies were equally enhanced by the F3 and the chimera vaccines before challenge and by the F3 vaccine after challenge (C,D). 


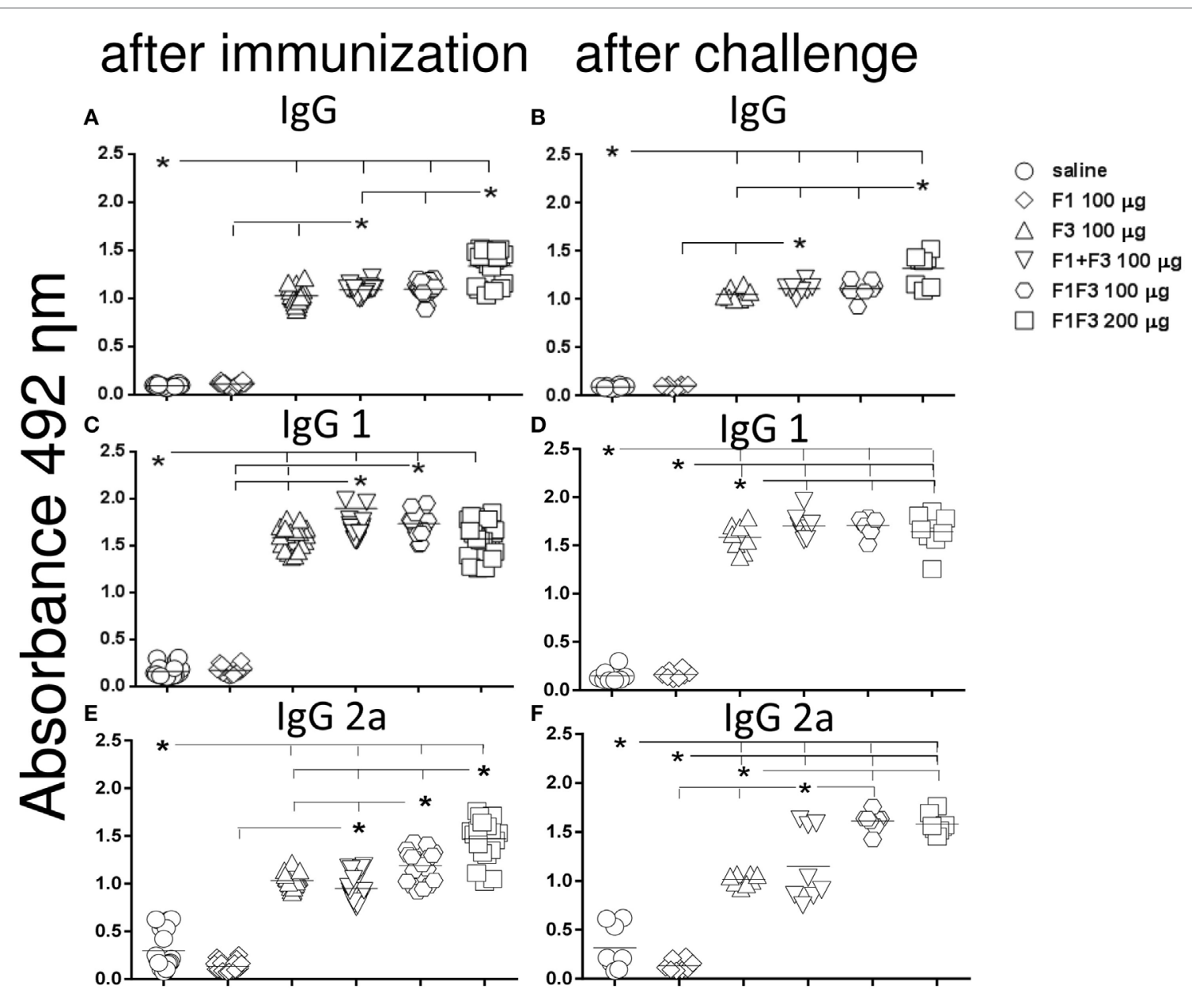

FIGURE 2 | Chimera increased the IgG, IgG1, and IgG2a antibody levels. Anti-NH36 antibodies were measured by an ELISA assay in the sera of mice vaccinated with F1, F3, the addition of F1 and F3, or the F1F3 chimera in formulation with saponin and after infection with Leishmania amazonensis. Data are means and individual results of two independent experiments, each one with 8-10 animals per treatment. The F1 protein alone did not induce any increase in IgG, IgG1, or IgG2a antibodies while the F3 did (A-F). The mixture of domains enhanced the IgG, IgG1, and lgG2a antibody responses above the F3 and F1 proteins (A-D,F). The chimera, however, induced the strongest lgG and lgG2a anti-NH36 responses (A-C,E,F) being, at the dosage of $100 \mu \mathrm{mg}$, more potent that the domain mixture

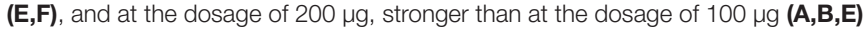

a dose-response effect (Figure 2E). Optimization of the IgG2a antibody response was also detected as a result of the impact of L. amazonensis infection when the two chimera-vaccine dosages showed a $28 \%$ increased potency above the F1 + F3 vaccine ( $p<0.007$ for the two comparisons) (Figure 2F).

For the IgG1 subtype, the admixed domains were as potent as the chimera $(100 \mu \mathrm{g})$ (Figures 2C,D).

We concluded that the presentation of the F1 and F3 proteins in a recombinant chimera determined a stronger effect than the simultaneous delivery of both independent domains, for the induction of $\operatorname{IgA}$, IgG, and IgG2a anti-NH36 antibodies. An increasing dose-response was additionally detected for the chimera in the IgG (before and after challenge) and IgG2a (before challenge) antibodies. In contrast, the chimera at the dosage of $100 \mu \mathrm{g}$ was even more potent than at $200 \mu \mathrm{g}$, for the IgA and IgM (before and after challenge) and IgG1 (after immunization) antibodies, and was as strong as at $200 \mu \mathrm{g}$ dosage, for the IgG1 and IgG2a (after challenge) response. These results suggest that the optimization effect is more related to the concomitant presentation of the F1 and F3 epitopes in tandem, rather than to an increased antigen concentration.

\section{The F1F3 Chimera Optimizes the Intradermal Response to $L$. amazonensis Antigen}

The induction a cellular immune response was initially assessed by IDR. At all times, all formulations developed more potent IDR reactions that the saline controls and the $\mathrm{F} 1$ vaccine $(p<0.0001$ for all comparisons) (Figures 3A-D). Maximal skin tests were achieved in mice vaccinated with the chimera (Figure 3 ).

Although the chimera at $100 \mu \mathrm{g}$ dosage was more potent than the admixed proteins (Figures $\mathbf{3 A}, \mathbf{B}, \mathbf{D}$ ), and the F3 vaccine (Figure 3D), the dosage of $200 \mu \mathrm{g}$ was the strongest formulation, which induced the largest skin tests (Figures 3A-D). In fact, at 


\section{after immunization}

\section{after challenge}
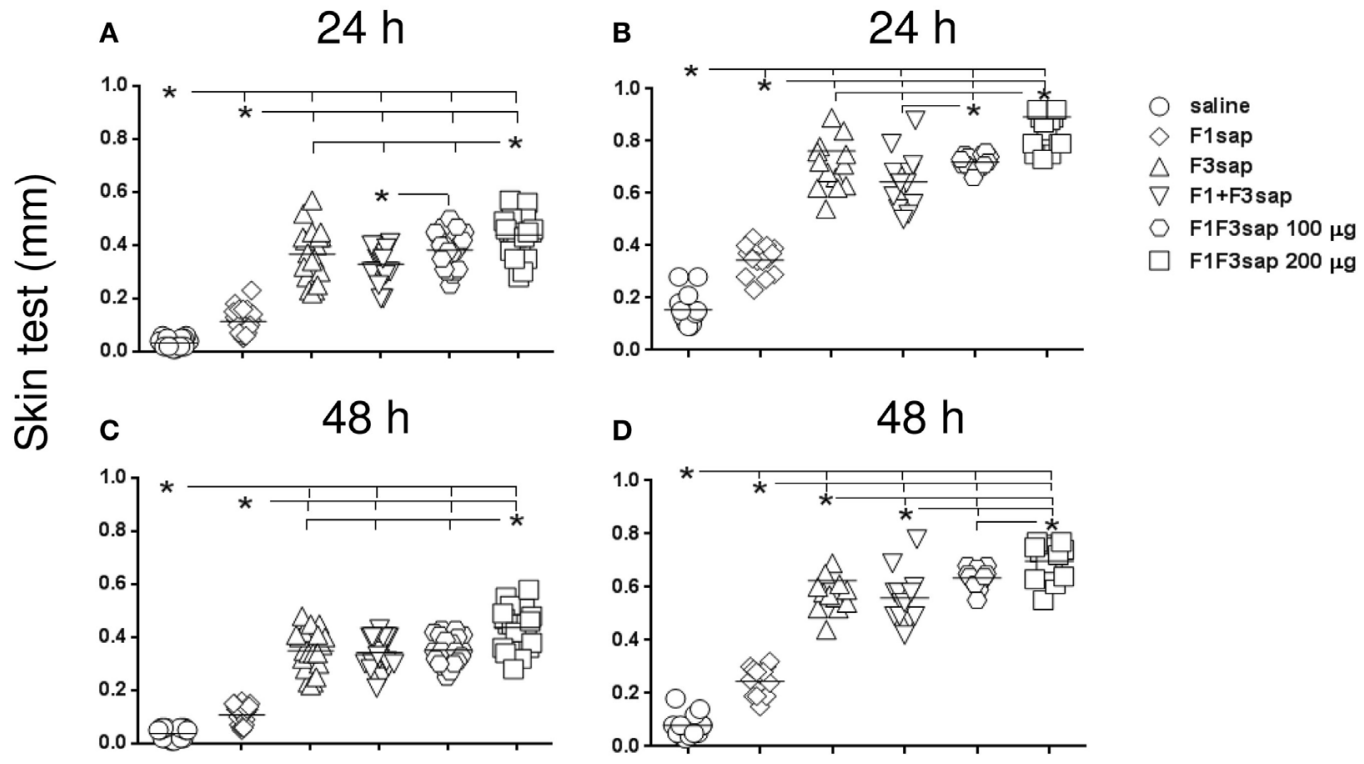

FIGURE 3 | Chimera optimizes the intradermal response against Leishmania amazonensis antigen. The IDR to the lysate of $L$. amazonensis infective promastigotes was measured in mice vaccinated with F1, F3, the addition of F1 and F3 proteins, or the F1F3 chimera, in formulation with saponin, after vaccination $(\mathbf{A}, \mathbf{C})$ and on week 12 after challenge with $L$. amazonensis (B,D), at 24 and $48 \mathrm{~h}$ after antigen injection. Data are means and individual results of two independent experiments, each one with 8-10 animals per treatment. All formulations were more potent than the saline controls and the F1 vaccine (A-D). The chimera, at $100 \mu \mathrm{g}$ dosage, was more potent than the addition of domains (A,B,D), and the F3 vaccine (D), but the dosage of $200 \mu \mathrm{g}$ was the strongest formulation (A-D). After challenge (B,D) and $48 \mathrm{~h}$ after antigen injection $(\mathbf{C}, \mathbf{D})$, all vaccines enhanced the skin tests.

the dosage of $100 \mu \mathrm{g}$, the chimera was already $13 \%$ more potent than the addition of $\mathrm{F} 1+\mathrm{F} 3$ proteins $(p<0.0232)$ disclosing the optimization effect that was due to the presentation of the epitopes in tandem. The additional 13\% $(p<0.0263)$ enhancement generated by the $200 \mu \mathrm{g}$ dosage disclosed a dose-response effect (Figure 3A).

After challenge, and in contrast to what described for antibodies, all the vaccines induced significant increases of skin tests $(p<0.0001)$. Actually, after infection, the skin tests of mice vaccinated with the F3, F1 + F3, 100, and $200 \mu \mathrm{g}$ chimera vaccines were $47,52,53$, and $51 \%$ larger than before challenge, respectively ( $p<0.0001$, for all comparisons) (Figures 3A,B). At $48 \mathrm{~h}$ after antigen injection also, respective IDR increases of $44,38,44$, and $38 \%$ were also observed for the F3, F1 + F3, 100, and $200 \mu \mathrm{g}$ chimera vaccines ( $p<0.0001$ for all comparisons) (Figures 3C,D).

Our results disclosed the chimera at the $200 \mu \mathrm{g}$ dosage as the strongest formulation. However, at the dosage of $100 \mu \mathrm{g}$, the chimera was already capable of inducing the most pronounced enhancement of skin tests after infection, being even more efficacious that the admixed domains. These results confirm the chimera capability for optimization of vaccine efficacy and suggest that efficacy could be even enhanced by using increased chimera dosages (Figures 3A-D).

The IDR response after immunization is highly correlated to the IgG $\left(p<0.0001, R=0.7552, R^{2}=0.5703\right)$ and the IgG2a $\left(p<0.0001, R=0.8839, R^{2}=0.7813\right)$ antibody responses. Also, after infection, the IgG $\left(p<0.0001, R=0.7009, R^{2}=0.4912\right)$ and IgG2a antibody levels $\left(p<0.0001, R=0.8364, R^{2}=0.6995\right)$ were correlated to the IDR results.

\section{Secretion of IFN- $\gamma$, TNF- $\alpha$, and IL-10 Increased in Response to the F1F3 Chimera}

After immunization, all vaccines increased the IFN- $\gamma$ secretion to PBMC supernatants above the levels induced by the saline controls $(p<0.0022)$, indicating the triggering of a Th1immune response. Mice vaccinated with F3-containing vaccines secreted more IFN- $\gamma$ than those treated only with the F1 protein $(p<0.0022)$. The main performance was, however, determined by the chimera at $100 \mu \mathrm{g}$ dosage, which was $19 \%$ stronger than the admixed domains and $20 \%$ more potent than the $200 \mu \mathrm{g}$ dosage ( $p<0.0022$ for both comparisons) (Figure 4A). After infection, and as observed for skin tests and IgG2a antibodies, the two dosages of the chimera showed codominance of the IFN- $\gamma$ secretion (Figure 4B) above the F1 and F3 vaccines independently or formulated together ( $p<0.0002$ for all comparisons). IFN- $\gamma$ levels induced by the chimeras after challenge were $56-44 \%$ lower (Figure 4B).

As observed for IFN- $\gamma$ and also indicating the rise of a Th1 response, TNF- $\alpha$ was initially more secreted by mice vaccinated with F3 than with F1 $(p<0.0022)$ (Figure 4C) and by all vaccines 

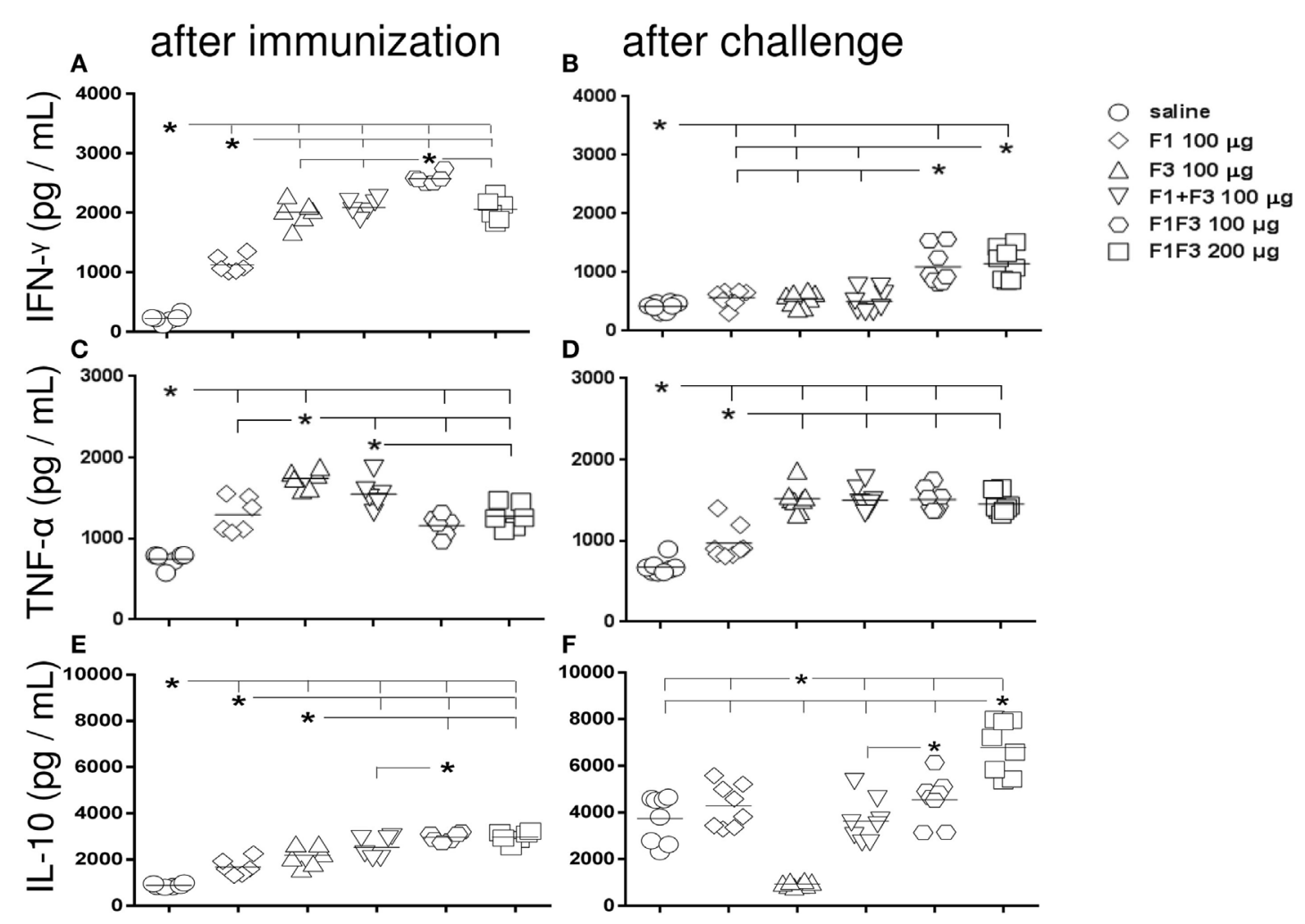

FIGURE 4 | Chimera potentiates the secretion of IFN- $\gamma$ and IL-10 while TNF- $\alpha$ is generated in response to all F3-containing vaccines. Secretions of IFN- $\gamma(\mathbf{A}, \mathbf{B})$, TNF- $\alpha(\mathbf{C}, \mathbf{D})$, and IL-10 (E,F), as measured by an ELISA assay in the supernatant of splenocytes, both after immunization with F1, F3, the addition of F1 and F3 proteins, or the F1F3 chimera in formulation with saponin, and after challenge with Leishmania amazonensis, are expressed in picograms per milliliter. Data are means and individual results of two independent experiments, each one with 8-10 animals per treatment. After immunization, the F3-containing vaccines secreted more IFN- $\gamma$ than the F1 vaccine. The chimera at $100 \mu \mathrm{g}$ dosage was stronger than the admixed proteins and the $200 \mu \mathrm{g}$ dosage (A). After infection, the two dosages of the chimera were equally potent (B) above the F1 and F3 vaccines independently or formulated together. However, the IFN- $\gamma$ levels after challenge were lower (B). TNF- $\alpha$ was initially more secreted by mice vaccinated with F3 than with F1 (C) and by all vaccines containing the F3 domain, after challenge (D). The chimeras or the admixed proteins enhanced IL-10 secretion after immunization, above the F1 or F3 vaccines (E). After challenge, IL-10 secretion was null in F3-vaccinated mice, but it was increased by the other vaccines with maximal performance achieved by the chimera (200 $\mu \mathrm{g})(\mathbf{F})$. A dose-response increase in IFN- $\gamma$ (B) and IL-10 (F) secretion was observed with the increment of the chimera dosage.

containing the F3 domain, including the chimeras, after challenge (Figure 4D).

Additionally and suggesting a potential regulatory immune response, mice vaccinated with the chimeras or with the admixed proteins secreted more IL-10 after immunization than mice vaccinated with F1 or F3 proteins alone $(p<0.015$ for all comparisons) (Figure 4E). Noteworthy, IL-10 secretion was higher in mice vaccinated with $100 \mu \mathrm{g}$ of the chimera than with the F1 + F3 addition, both before and after challenge (Figures 4E,F).

Remarkably, after challenge, however, IL-10 secretion was null only in F3-vaccinated mice while it was increased by all vaccines containing $\mathrm{F} 1$ and achieved the maximal values in the $200 \mu \mathrm{g}$ chimera vaccine (Figure 4F). In fact, after infection, the IL-10 levels were 2.3 times reduced $(p<0.0007)$ in F3-vaccinated mice, while increases of $2.6(p<0.0007), 1.4(p<0.0200), 1.5$ $(p<0.0023)$, and 2.3 times $(p<0.0007)$ were detected in mice vaccinated with the F1, F1 + F3, and the chimera vaccine at 100 and $200 \mu \mathrm{g}$ dosage, respectively (Figures 4E,F).
Lastly, a dose-response increase in IFN- $\gamma$ and IL-10 secretion was observed with the increment of the chimera dosage to $200 \mu \mathrm{g}$.

\section{The F1F3 Chimera Induces the Highest Proportions of CD4+ and CD8+ T Cells Secreting One, Any Combination of Two and Three Cytokines}

The effector function and quality of the $\mathrm{T}$ cell immune response were assessed after infection, by multiparameter-flow cytometry analysis.

The chimera vaccine at $100 \mu \mathrm{g} /$ dose induced the highest proportions of all types of CD4+-cytokine secreting $\mathrm{T}$ cells (Figure 5). In fact, the $100 \mu \mathrm{g} /$ dose chimera was more potent than the F3 $(p<0.0469)$ and F1 $+\mathrm{F} 3$ vaccines $(p<0.0391)$ inducing elevated proportions of CD4+ T cells secreting IL-2, TNF- $\alpha$, or IFN- $\gamma$ alone (Figures 5A-C), TNF- $\alpha$ in combination 


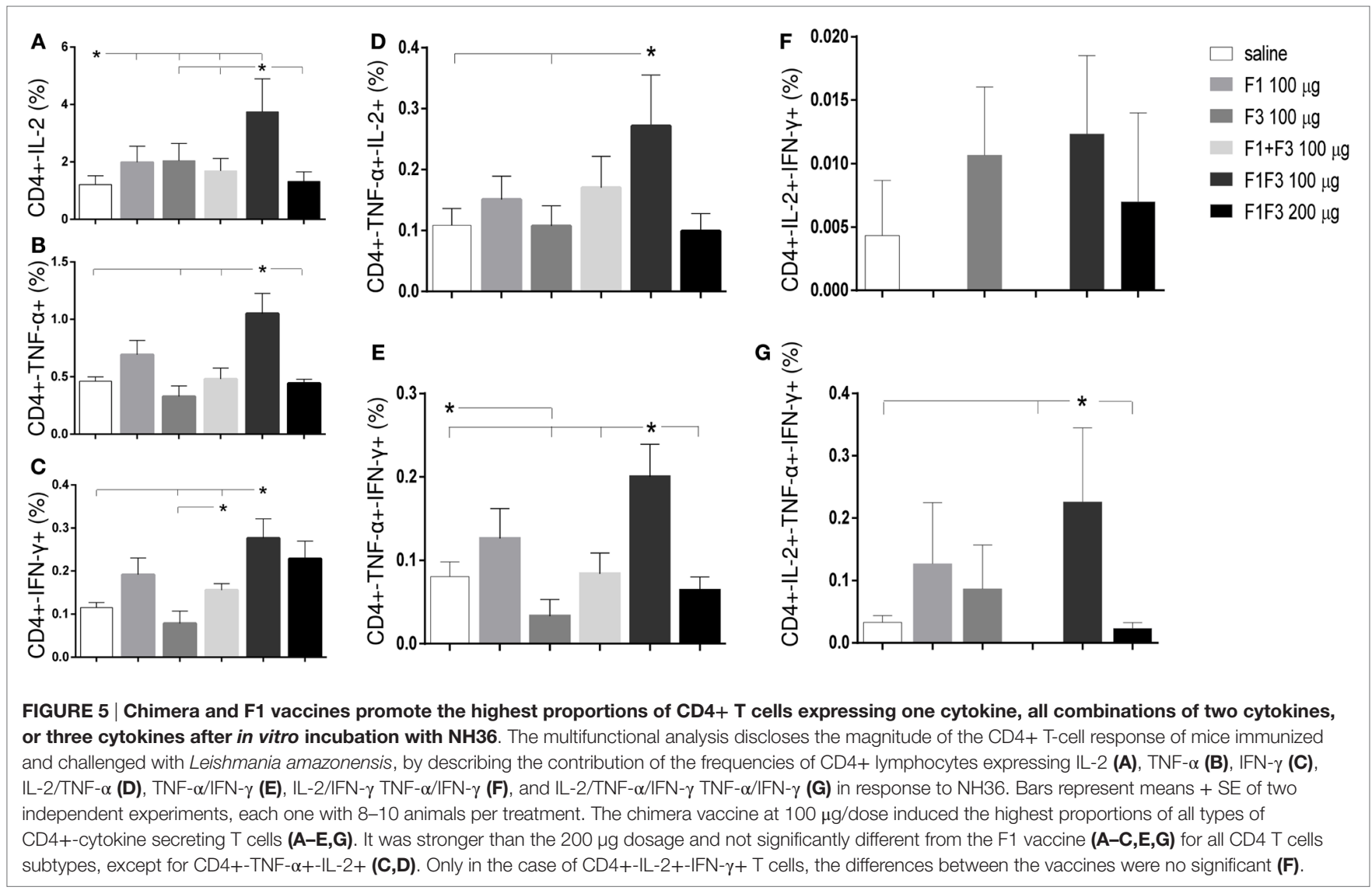

with IL-2 or IFN- $\gamma$ (Figures 5D,E) and multifunctional cells secreting IL-2, TNF- $\alpha$, and IFN- $\gamma$ simultaneously (Figure 5G). Additionally, the $100 \mu \mathrm{g}$ dose was stronger than the $200 \mu \mathrm{g}$ dosage $(p<0.0391)$ and not significantly different than the F1 vaccine (Figures 5A-C,E,G) for all CD4 T cells subtypes, except for CD4+-TNF- $\alpha+-$ IL-2+ (Figures 5C,D). Our results indicate the presence of important CD4+ epitopes in F1 (Figures 5A-E,G) and suggest that the presentation of the epitopes in tandem by the chimera represents the best approach for optimization of the Th1 response. Only in the case of CD4+-IL-2+-IFN- $\gamma+\mathrm{T}$ cells, the differences between the vaccines were no significant (Figure 5F).

Regarding the cytotoxic response (Figure 6), the admixed proteins were not capable of inducing higher CD8+ T cell proportions than the F1 or F3 domains independently (Figure 6). Furthermore, as described for CD4+ T cells (Figure 5), the chimera vaccine, at the dosage of $100 \mu \mathrm{g}$, also promoted the highest proportions of CD8+ T cell expressing IL-2, TNF- $\alpha$, or IFN- $\gamma$ (Figures 6A-C) and TNF- $\alpha$, in combination with IL-2 or IFN- $\gamma$ (Figures 6D,E). This did not occur for the CD8+ multifunctional $\mathrm{T}$ cells which, in contrast to what observed for CD4+ $\mathrm{T}$ cells, showed no significant differences between treatments (Figures 6F,G).

At $100 \mu \mathrm{g}$ dosage, the chimera was more potent than at $200 \mu \mathrm{g}$ for the increase of the proportions of CD8+-TNF- $\alpha+$ $(p<0.0078)$ and CD8+-IFN- $\gamma+$ secreting T cells $(p<0.0078)$.
Additionally, and similar to what described for CD4+ T cells (Figure 5), the $100 \mu \mathrm{g}$ chimera vaccine was stronger than the F3 vaccine in CD8+-TNF- $\alpha+-$ IFN- $\gamma$ T cells and as potent as the F1 vaccine in induction of most types of CD8+-cytokine secreting $\mathrm{T}$ cells (Figures 6A,B,D,E), except for cells secreting only IFN- $\gamma$ (Figure 6C). Our results also indicate that important epitopes for $\mathrm{CD} 8+\mathrm{T}$ cells are located in the $\mathrm{F} 1$ domain.

The multifunctional flow cytometry confirmed that in order to optimize the antigen presentation to $\mathrm{T}$ cells, the exposure of the F1 and F3 domains cloned in tandem is needed. The simple addition of the two domains was not effective in triggering the cellular immune response. We conclude that the chimera at the dosage of $100 \mu \mathrm{g}$ generated the strongest protection against the parasite challenge but was not significantly different from the F1 vaccine.

\section{Vaccine Efficacy Is Optimized by the F1F3 Chimera Formulation}

The evolution of the infection was monitored by the increase of the skin lesion sizes up to week 12 after infection. The linear regression analysis revealed significantly different degrees of vaccine-induced protection disclosed by the decreased slopes of their respective curves: $0.3033 \pm 0.016$ for the F1, $0.2257 \pm 0.012$ for the F3, $0.1973 \pm 0.009$ for the F1 + F3, $0.1793 \pm 0.008$ for the F1F3 $100 \mu \mathrm{g}$, and $0.1640 \pm 0.007$ for 


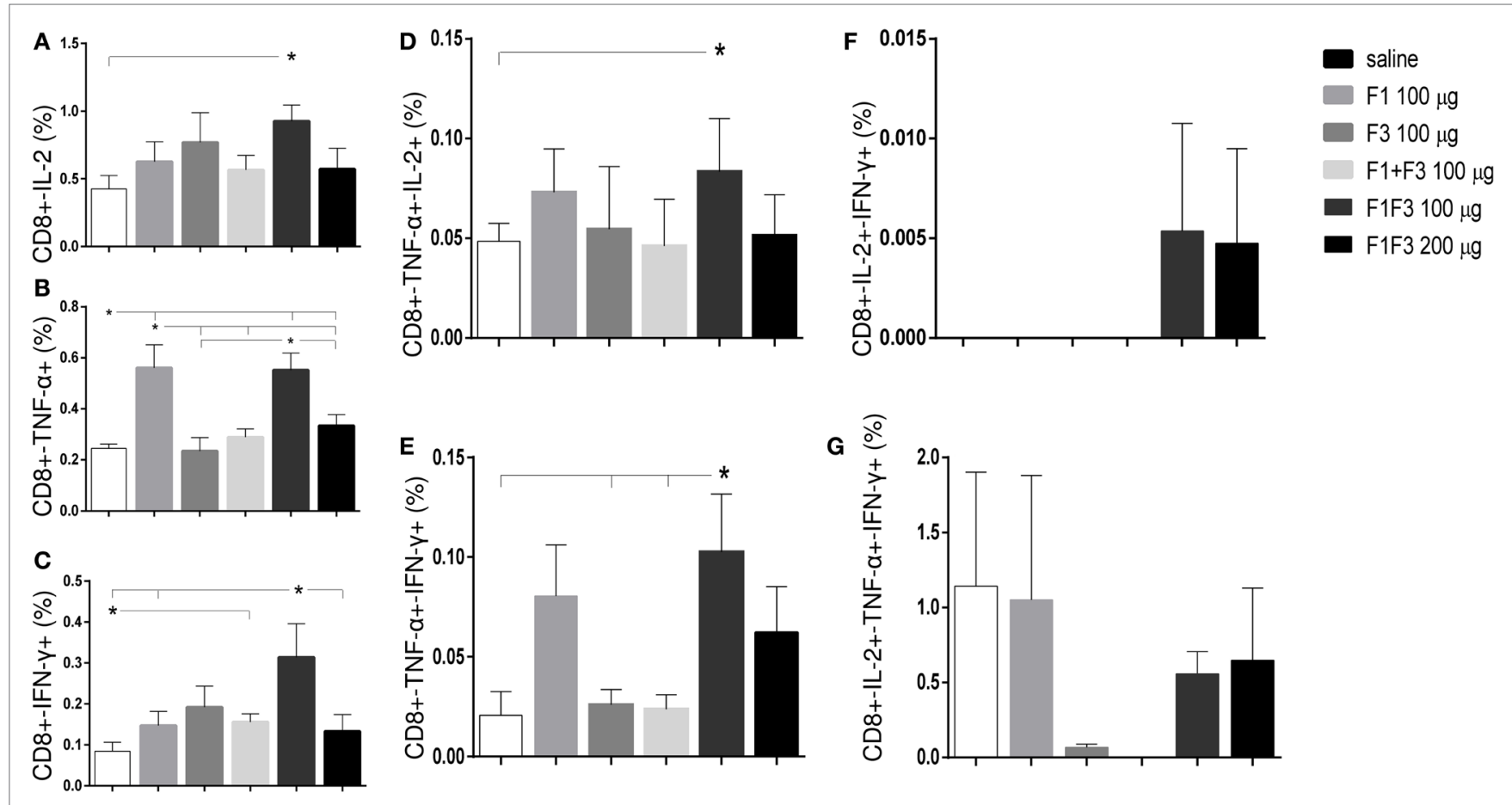

FIGURE 6 | Chimera and F1 vaccines generate the highest proportions of CD8+ T cells expressing one cytokine, all combinations of two cytokines, or three cytokines after in vitro incubation with NH36. The magnitude of the cytotoxic T-cell response is revealed by the cytometry-multifunctional analysis, which disclosed the frequencies of CD8+ lymphocytes expressing IL-2 (A), TNF- $\alpha$ (B), IFN- $\gamma$ (C), IL-2/TNF- $\alpha$ (D), TNF- $\alpha /$ IFN- $\gamma$ (E), IL-2/IFN- $\gamma$ TNF- $\alpha /$ IFN- $\gamma$ (F), and IL-2/TNF- $\alpha /$ IFN- $\gamma$ TNF- $\alpha /$ IFN- $\gamma$ (G) in response to NH36, of mice vaccinated with F1, F3, the addition of F1 and F3, or the F1F3 chimera and challenged with Leishmania amazonensis. Bars represent means + SE of two independent experiments, each one with 8-10 animals per treatment. The admixed proteins were not capable of inducing higher CD8+ T cell proportions than the F1 or F3 vaccines. The chimera vaccine (100 $\mu \mathrm{g})$ promoted the highest proportions of CD8+ T cell expressing all combination of cytokines (A-E) except for the CD8+ multifunctional T cells $(\mathbf{G})$ and was more potent than at $200 \mu \mathrm{g}$ for the increase of the proportions of CD8+-TNF- $\alpha+\mathbf{( B )}$ and CD8+-IFN- $\gamma+$ secreting T cells (C). The $100 \mu \mathrm{g}$ chimera vaccine was also stronger than the F3 vaccine in CD8+-TNF- $\alpha+-I F N-$ $\gamma T$ cells and as potent as the F1 vaccine in induction of most types of CD8+-cytokine secreting T cells $(\mathbf{A}, \mathbf{B}, \mathbf{D}, \mathbf{E})$.

the F1F3 $200 \mu \mathrm{g}$ vaccines. Except for the F1 vaccine, all formulations induced protection and decreased the lesion sizes in comparison to saline controls ( $p<0.0351$ for all comparisons) (Figure 7A). Furthermore, the F1 + F3 vaccine and the chimeras were more efficacious than the $\mathrm{F} 1$ vaccine $(p<0.0500)$ (Figure 7A) and equally potent until week 8 after infection. By the end of the experiment, on week 12, however, the strongest reduction in lesion sizes was determined by the combination of F1 + F3 domains and by the chimera, at the 100 and $200 \mu \mathrm{g}$ dosages, which induced 80,82 , and $84 \%$ of protection, respectively (Figure 7A).

Additionally, the parasite load was evaluated after euthanasia by a limiting dilution assay on week 12 after infection (Figure 7B). While the saline controls exhibited 1,259,770 promastigotes, the chimera vaccines at $100 \mu \mathrm{g} /$ dose decreased the parasite load to $2,423(p<0.0040)$ and at $200 \mu \mathrm{g} / \mathrm{dose}$, to $1,424(p<0.0062)$. Our results indicate that the presentation of epitopes in tandem in a recombinant chimera exceeds the protection generated by the mixture of the recombinant domains F1 and F3. In fact, efficacies of 99.8 and $99.9 \%$ were achieved using the chimera at 100 and $200 \mu \mathrm{g} / \mathrm{dose}$, respectively. The measures of footpad lesions at week 12 after infection and the $\log _{10}$ number of parasites in lesions were highly correlated $\left(p<0.001, R=0.5640, R^{2}=0.3181\right)$.

The increases in the antibody response were good surrogates for protection. In fact, we detected significant negative correlations between the increase of all antibody subtypes and the decrease of footpad lesion sizes and of the number of parasites. The IgG2a increase for instance was negatively correlated to the size of footpad lesions $(p<0.0001, R=-0.6026$ before and $p=0.0029, R=-0.4246$ after infection) and to the number of parasites in lesions ( $p=0.0293, R=-0.3147$ before and $p=0.0031, R=-0.4177$ after infection).

Additionally, the IDR $(p<0.0001, R=-0.7815)$ and the frequencies of multifunctional CD4+ $(p<0.0500, R=-0.2803)$ and CD8+ T cells ( $p<0.0001, R=-0.7837)$ expressing IL-2, TNF- $\alpha$, and IFN- $\gamma$, after infection, were strong correlates of prophylactic efficacy. In agreement to that, the number of parasites in lesions was also negatively correlated with the $\operatorname{IDR}(p=0.0012$, $R=-0.4531)$ and the CD8 T cells expressing IL-2, TNF- $\alpha$, and IFN- $\gamma(p=0.0012, R=-0.4531)$.

We conclude that vaccination with the F1F3 chimera optimizes the cross-species vaccine efficacy against L. amazonensis infection above the levels reached by the admixed domains. 


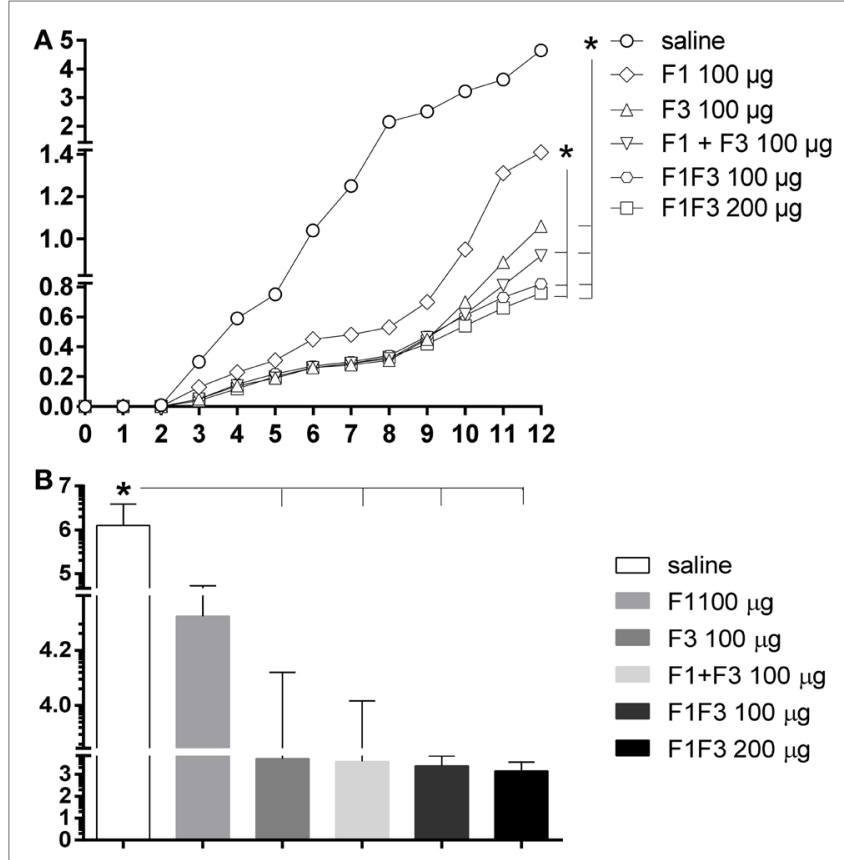

FIGURE 7 | Chimera optimized the vaccine efficacy by inducing the strongest reductions in sizes and parasite load of the skin lesions. $\mathrm{BALB} / \mathrm{c}$ mice were immunized with three subcutaneous doses of F1, F3, F1 and F3 (F1 + F3), or F1F3 chimera (100 or $200 \mu \mathrm{g}$ ) formulated in saponin and were challenged with Leishmania amazonensis. The evolution of footpad lesion sizes was weekly monitored with a pachymeter $(\mathbf{A})$. The values of the infected right hind-footpads were discounted from those of the contra-latera left hind-footpads injected with saline. The parasite load in the skin lesion was measured after euthanasia by a limiting dilution assay on day 4 after in vitro culture (B). Data represent means (A) and means + SE (B) of two independent experiments, each one of them with 8-10 animals per treatment. Except for the F1 vaccine, all formulations induced protection and decreased the lesion sizes in comparison to saline controls (linear regression analysis) (A). The F1 + F3 vaccine and the chimeras were stronger than the $\mathrm{F} 1$ vaccine but, on week 12, however, the strongest reductions in lesion sizes were determined by the combination of F1 + F3 domains (80\%) and by chimera at the $100 \mu \mathrm{g}(82 \%)$ and $200 \mu \mathrm{g}(84 \%)$ dosages (A). The parasite load, on the other hand, revealed efficacies of 99.8 and $99.9 \%$ developed by the chimeras at 100 and $200 \mu \mathrm{g} /$ dose, respectively (B).

\section{CD4+ and CD8+ T-Cell Epitopes of the F1 and F3 Domains Exceed the Cellular Immune Response Generated by the Chimera}

Toward the design of a potential synthetic vaccine, we further investigated which of the predicted F1 and F3 domains' T-cell epitopes target the optimized cellular immune response and induce in vitro $\mathrm{T}$ cell responses even stronger than the chimera.

The in silico prediction for $\mathrm{CD} 4+\mathrm{T}$ cell epitopes performed before (17) mapped two sequences of CD4+ $\mathrm{T}$ cell epitopes of BALB/c mice in F1 (ELLAITTVVGNQ and DVAGIVGVPVAAGCT) and three more sequences in the F3 domain (FMLQILDFYTKVYE, FRYPRPKHCHTQVA, and KFWCLVIDALKRIG) (Table 1). Additionally, the highest scored CD8+ epitope (YPPEFKTKL) of the NH36 protein was identified in the F1 domain (17) (Table 1). We here compared the secretion
TABLE 1 | IFN- $\gamma / \mathrm{IL}-10$ and TNF- $\alpha / \mathrm{IL}-10$ ratios secreted in response to the predicted synthetic epitopes of $\mathrm{NH} 36$.

\begin{tabular}{llllll}
\hline $\begin{array}{l}\text { Amino acid } \\
\text { location }^{\mathbf{a}}\end{array}$ & $\begin{array}{l}\text { Predicted } \\
\text { for }\end{array}$ & Domain & Sequences & $\begin{array}{c}\text { IFN- } \boldsymbol{\gamma} \text { / } \\
\text { IL-10 }\end{array}$ & $\begin{array}{c}\text { TNF- } \boldsymbol{\alpha} \text { / } \\
\text { IL-10 }\end{array}$ \\
\hline 0219-40 & CD4 & F1 & ELLAITTWGNQ & 0.18 & 0.81 \\
$54-68$ & CD4 & F1 & DVAGIVGVPVAAGCT & 0.14 & 0.59 \\
$92-100$ & CD8 & F1 & YPPEFKTKL & 0.96 & 0.49 \\
$217-230$ & CD4 & F3 & FMLQILDFYTKVYE & 0.64 & 0.60 \\
$278-291$ & CD4 & F3 & FRYPRPKHCHTQ & 0.92 & 1.72 \\
$298-311$ & CD4 & F3 & KFWCLVIDALKRIG & 0.29 & 1.00 \\
\hline
\end{tabular}

aThe in silico predicted epitopes for CD4+ and CD8+ lymphocytes of Balb/c mice were previously described by Nico et al. (17).

of cytokines induced by each one of these epitopes alone or mixed together, using the NH36 and F1F3 chimera antigens as controls, in mice vaccinated with the chimera, on week 11 after L. amazonensis challenge.

Actually, several epitopes induced higher cytokine secretion than the NH36 and their chimera cognate proteins in vaccinated mice and that their controls in saline treated mice. Among them, remarkably, the YPPEFKTKL epitope of F1 and the FMLQILDFYTKVYE epitope of the F3 domain promoted the highest levels of IFN- $\gamma$ (Figure 8A), and together with ELLAITTVVGNQ and DVAGIVGVPVAAGCT epitopes, also the strongest secretion of TNF- $\alpha$ (Figure $8 B$ ) and IL-10 (Figure 8C).

In contrast, the two other CD4+ predicted epitopes of F3, FRYPRPKHCHTQVA and KFWCLVIDALKRIG, induced a moderate but significant secretion of TNF- $\alpha$ (Figure $8 B$ ) and no secretion or poor levels of IL-10 (Figure 8C), respectively, when compared to the untreated saline controls.

These results suggested the induction of a mixed Th1/Th2 immunity in response to the FMLQILDFYTKVYE of F3, and the YPPEFKTKL, ELLAITTVVGNQ, and DVAGIVGVPVAAGCT predicted epitopes of the F1 domain. In contrast, the two final CD4 predicted epitopes of F3, FRYPRPKHCHTQVA and KFWCLVIDALKRIG generated a main Th1 response, with a predominant TNF- $\alpha$ production and low IL-10 secretion (Figure 8).

Calculation of the IFN- $\gamma /$ IL-10 and TNF- $\alpha /$ IL-10 secreted ratios confirmed the generation of the Th1 response (Table $\mathbf{1}$ ). In fact, the FRYPRPKHCHTQVA sequence of F3 induced an elevated IFN- $\gamma / \mathrm{IL}-10$ and the highest TNF- $\alpha / \mathrm{IL}-10$ ratio. The KFWCLVIDALKRIG epitope also generated a high TNF- $\alpha /$ IL-10 ratio, which was followed by the ELLAITTVVGNQ sequence. Interestingly, the YPPEFKTKL epitope also promoted a high IFN- $\gamma /$ IL-10 ratio (Table $\mathbf{1}$ ).

The multiparameter cytometry analysis disclosed that the FRYPRPKHCHTQVA epitope as the most potent enhancer of the CD4+-TNF- $\alpha$, -IFN- $\gamma$, -TNF- $\alpha$-IL- 2 , -TNF- $\alpha-$ IFN- $\gamma$ and -IFN- $\gamma$-IL-2 T cell proportions (Figure 9), confirming its capability of raising a specific Th1 response (Figures 8B,C). The YPPEFKTKL epitope was the second most important sequence which, although predicted as a CD8 epitope, also stimulated the increase of the proportions of CD4+ T cells producing TNF- $\alpha$, IFN- $\gamma$, IL-2-IFN- $\gamma$ and TNF- $\alpha$-IFN- $\gamma$, as much as the chimera did (Figure 9). Additionally, the multifunctional IL-2-TNF- $\alpha$ IFN- $\gamma$-secreting CD4+ T-cells were only raised in response to the 


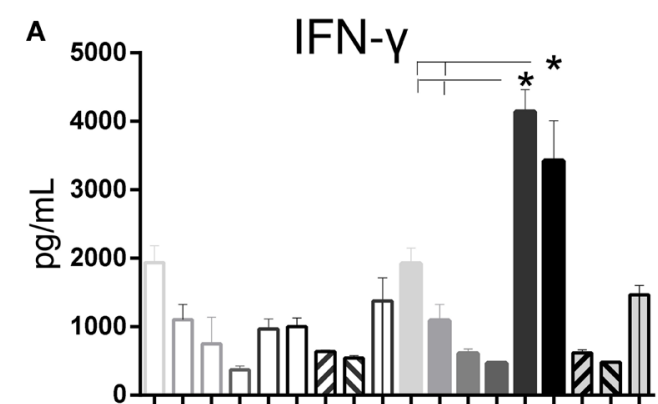

B
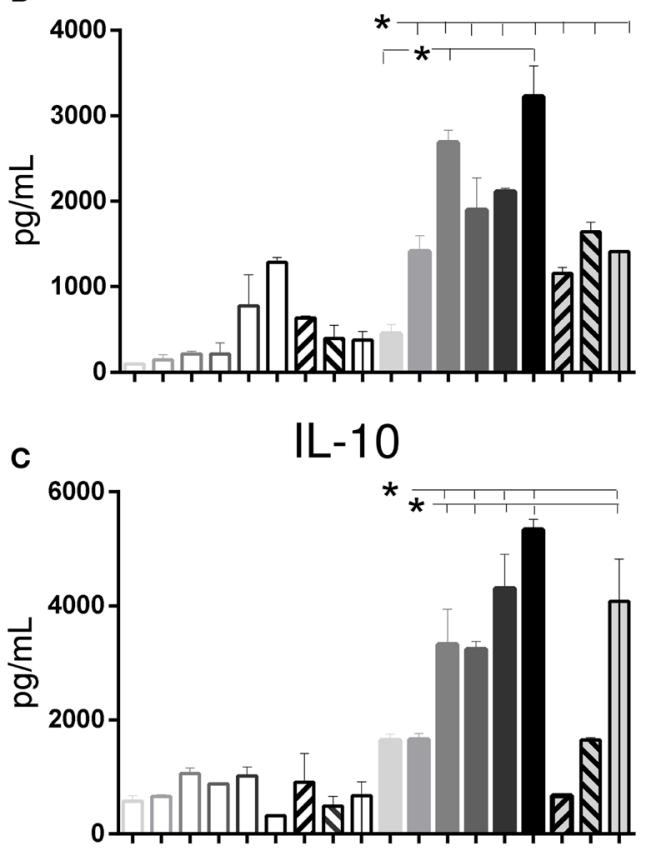

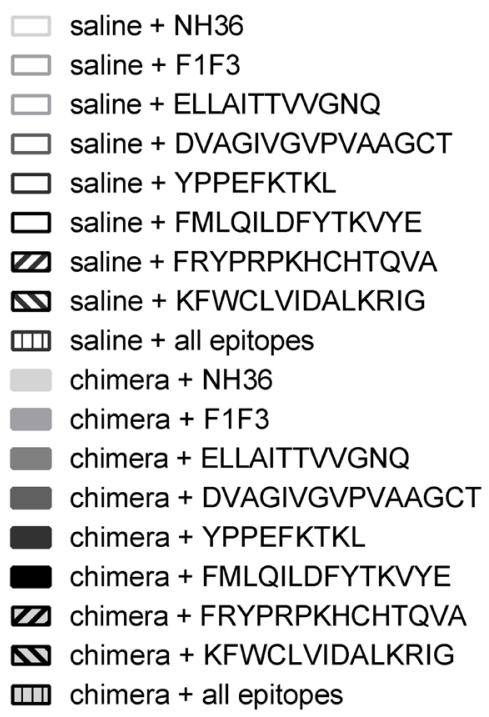

FIGURE 8 | The YPPEFKTKL and FMLQILDFYTKVYYE epitopes promote the highest IFN- $\gamma$ and IL-10 levels, and together with DVAGIVGVPVAAGCT and ELLAITTVVGNQ, the strongest TNF- $\alpha$ secretion of splenocytes of chimera-vaccinated mice. Splenocytes of mice vaccinated with $100 \mu \mathrm{g}$ of the chimera were incubated in vitro with $10 \mu \mathrm{g} / \mathrm{ml}$ of NH36, F1F3 chimera, each one of the CD4 predicted epitopes of F1 (ELLAITTVVGNQ and DVAGIVGVPVAAGCT) and F3 domains (FMLQILDFYTKVYE, FRYPRPKHCCHTQVA, and KFWCLVIDALKRIG) and with the highest scored CD8 predicted epitope of the F1 protein (YPPEKTKL), or with the mixture of all the epitopes, at week 11 after infection. Secretions of IFN- $\gamma$ (A), TNF- $\alpha$ (B), and IL-10 (C) were measured by an ELISA assay in the supernatants of splenocytes and expressed in picograms per milliliter. Data are means + SE of two independent experiments, each one with 8-10 animals per treatment. The YPPEFKTKL epitope of F1 and the FMLQILDFYTKVYE epitope of the F3 domain promoted the highest levels of IFN- $\gamma$ (A), and together with ELLAITTWGNQ and DVAGIVGVPVAAGCT epitopes, also the strongest secretion of TNF- $\alpha$ (B) and IL-10 (C). In contrast, the FRYPRPKHCHTQVA and KFWCLVIDALKRIG of F3 induced a moderate but significant secretion of TNF- $\alpha$ (B) and no secretion or poor levels of IL-10 (C).

FRYPRPKHCHTQVA, FMLQILDFYTKVYE, and the admixed epitopes. In contrast, no epitope increased the percent of CD4+ T cells secreting only IL-2 above the levels promoted by the chimera (Figure 9).

Regarding the cytotoxic response, YPPEFKTKL was the most potent epitope. Alone, it induced higher proportions of CD8+ T cells secreting IFN- $\gamma$ and IFN- $\gamma$ in combination with IL-2 than the chimera; together with DVAGIVGVPAAGCT and KFWCLVIDALKRIG, the highest frequencies of CD8+-IL-2+ $\mathrm{T}$ cells and combined only with DVAGIVGVPAAGCT, the highest proportions of CD8+-TNF- $\alpha+-$ IFN- $\gamma+\mathrm{T}$ cells. Furthermore, DVAGIVGVPAAGCT was the only epitope to increase the frequencies of CD8+-TNF- $\alpha+-\mathrm{IL}-2+\mathrm{T}$ cells (Figure 10). In contrast, the cytotoxic $\mathrm{T}$ cells secreting only TNF- $\alpha$ were increased in response to the ELLAITTVVGNQ and the FMLQILDFYTKVYE epitopes (Figure 10).

\section{DISCUSSION}

NH36 is an important phylogenetic marker, highly conserved among the species of the Leishmania genus. Thus, it became a strong candidate antigen for the development of a bivalent crossprotective vaccine against both visceral and CL $(17,28,29,38)$. We previously demonstrated that the F3 protein of NH36 hosts 


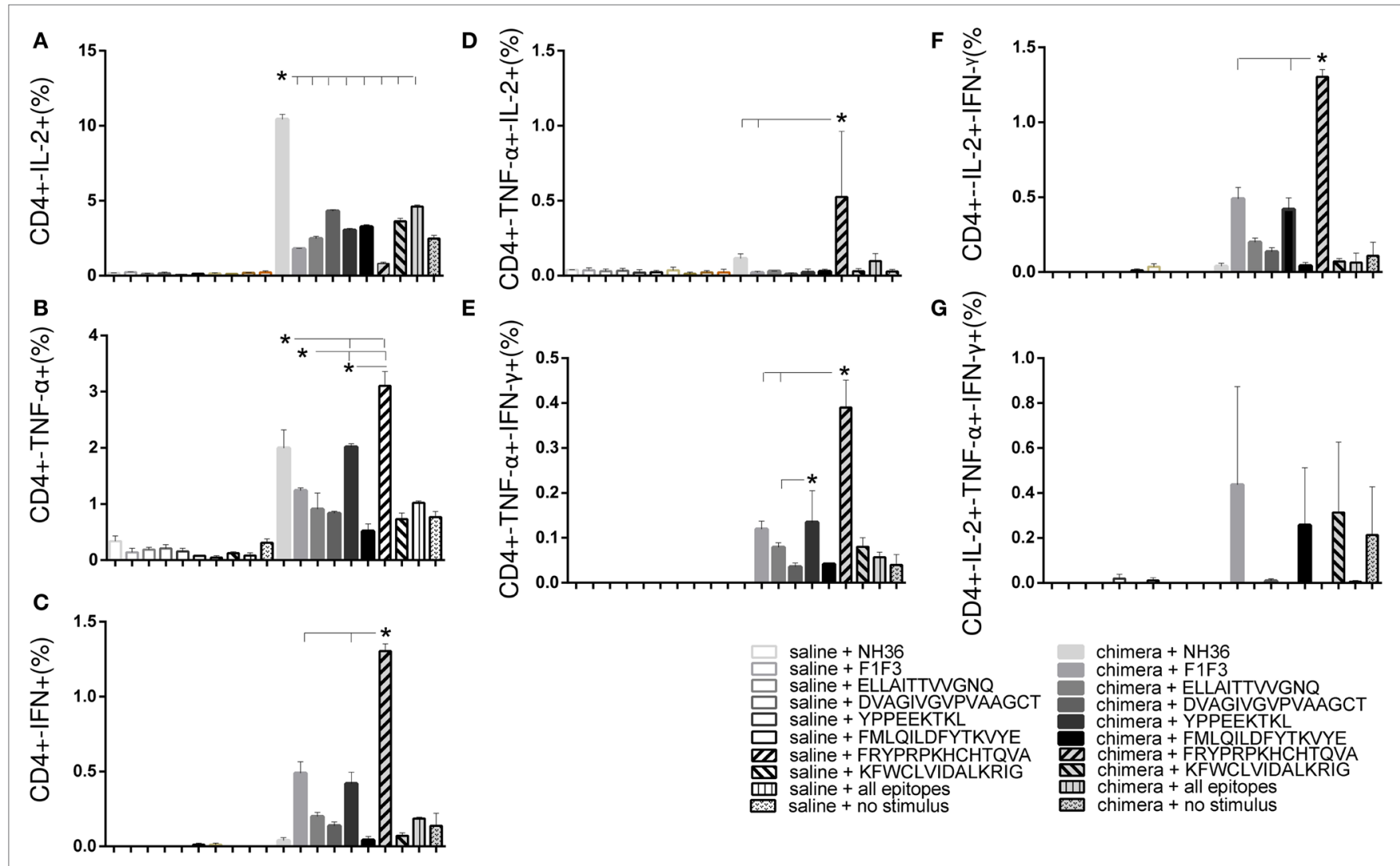

FIGURE 9 | Multiparameter cytometry analysis disclosed that the FRYPRPKHCHTQVA followed by the YPPEFKTKL epitopes induced the most potent CD4+ T cell response. Splenocytes of chimera-vaccinated mice were incubated with NH36, the chimera, the ELLAITTVVGNQ, DVAGIVGVPVAAGCT, YPPEKTKL, FMLQILDFYTKVYE, FRYPRPKHCCHTQVA, and KFWCLVIDALKRIG sequences, or with the mixture of all the epitopes, at week 11 after infection. The magnitude of the CD4+ T cell response was disclosed by the frequencies of the CD4+ lymphocytes expressing IL-2 (A), TNF- $\alpha$ (B), IFN- $\gamma$ (C), IL-2/TNF- $\alpha$ (D), TNF- $\alpha /$ IFN- $\gamma(\mathbf{E})$, IL-2/IFN- $\gamma$ TNF- $\alpha / I F N-\gamma$ (F), and IL-2/TNF- $\alpha / I F N-\gamma$ TNF- $\alpha / I F N-\gamma$ (G) in response to each antigen. Bars represent means + SE of two independent experiments, each one with 8-10 animals per treatment. The FRYPRPKHCHTQVA epitope induced maximal CD4+-TNF- $\alpha,-I F N-\gamma,-T N F-\alpha-I L-2,-T N F-\alpha-I F N-\gamma$, and -IFN- $\gamma$-IL-2 T cell proportions, confirming its capability of raising a specific Th1 response. The YPPEFKTKL epitope was the second most important sequence to enhance the proportions of CD4+ T cells producing TNF- $\alpha$, IFN- $\gamma$, IL-2-IFN- $\gamma$, and TNF- $\alpha$-IFN- $\gamma$. The IL-2-TNF- $\alpha$-IFN- $\gamma$-secreting CD4+ T-cells were only raised in response to the FRYPRPKHCHTQVA, FMLQILDFYTKVYE, and the admixed epitopes. In contrast, the chimera promoted the strongest CD4+-IL-2 T cell response.

the immunodominant CD4+ epitopes necessary for protection against $L$. chagasi $(17)$ and $L$. amazonensis $(17,28)$ infections. Instead, the F1 protein codominance with $\mathrm{F} 3$, in protection against $L$. amazonensis infection, is mediated mostly by CD8+ epitopes (28). Accordingly, the highest scored epitope for CD8+ $\mathrm{T}$ cells, YPPEFKTKL, was identified in the sequence of the F1 protein (17). The finding of $93 \%$ sequence homology between the NH36 of L. donovani and the A34480 NH of L. amazonensis encouraged even more the idea of a $\mathrm{NH}$-based bivalent vaccine against both leishmaniasis (28).

According to the philosophy of the $\mathrm{T}$ cell polytope vaccine development, efficacy increases using antigens that contain enriched proportions of the relevant epitopes $(34,35)$. Searching for the optimization of the vaccine efficacy against $L$. amazonensis infection, in this investigation, we used the F1 and F3 domains of NH36 through several approaches. First, we investigated if the simple mixture of F1 and F3 vaccines increased the efficacy above the levels induced by the F1 and F3 vaccines independently. Second, we asked if the presentation of F1 and F3 domains cloned in tandem, as a chimera, was more efficacious than the presentation of the admixed proteins. Third, we assayed if the chimerainduced protection could be enhanced in a dose-response manner by doubling the vaccine concentration. Finally, we identified the most important epitopes for CD4+ and CD8+ T cells included in the chimera that could be combined in a future synthetic polytope vaccine capable to induce cross-protection to CL.

Confirming that the F3 and F1 domains contain the epitopes responsible for the NH36-induced immune protection, higher efficacy was obtained by vaccination with each one of these proteins rather than with the whole NH36 cognate protein $(17,28,29,33)$. Additionally, the cross-protective capabilities of the NH36 vaccines can be explained by the high identity of the sequences of predicted epitopes of the two Leishmania NHs (28). In fact, the CD4+ epitope ELLAITTVVGNQ and the CD8+ epitope YPPEFKTKL of the F1 domain of NH36 (17) are completely conserved in the sequence of NH A34480 of L. amazonensis (28). Likewise, the DVAGIVGVPVAAGCT epitope for CD4+ T cells of F1, and the three epitopes for CD4+ 

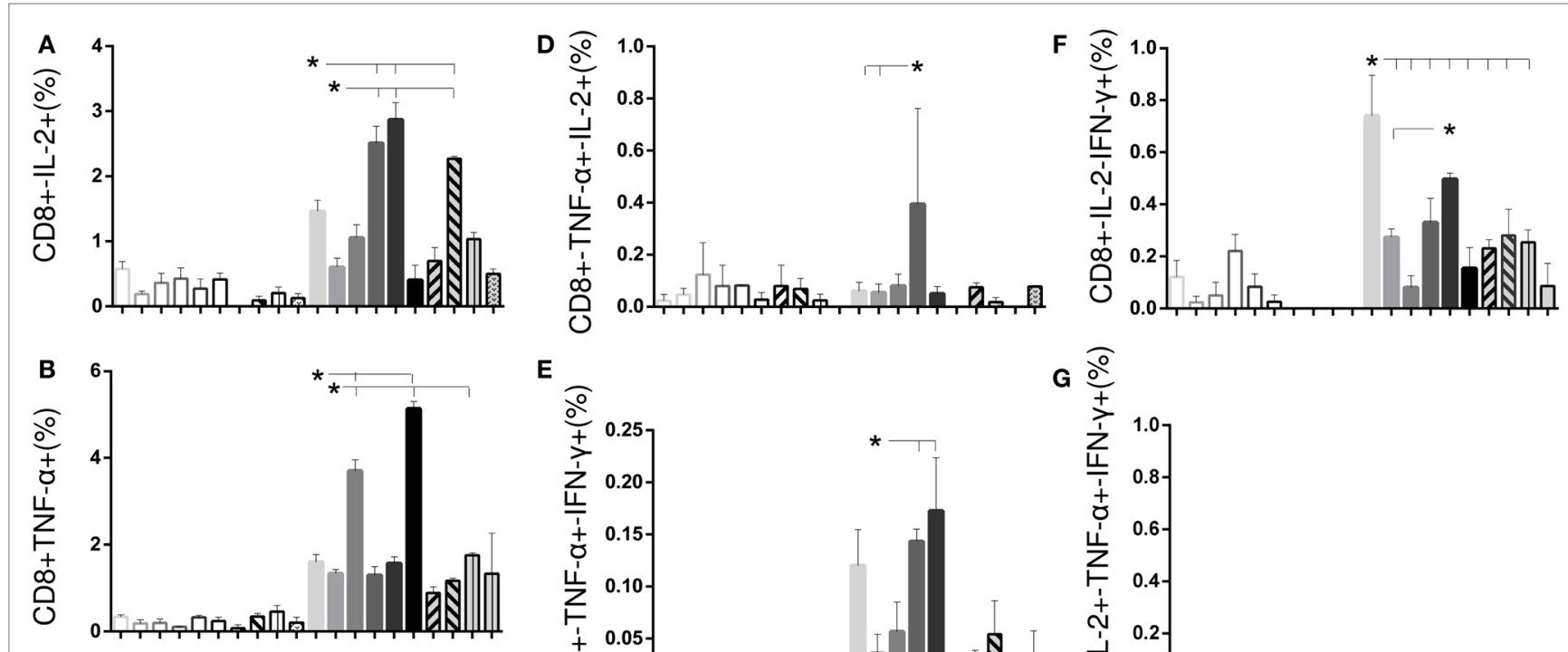

E

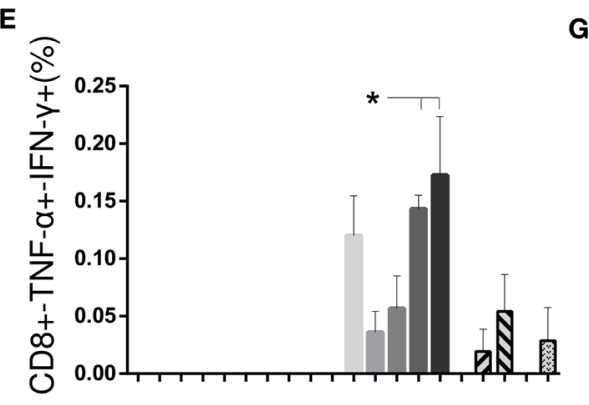

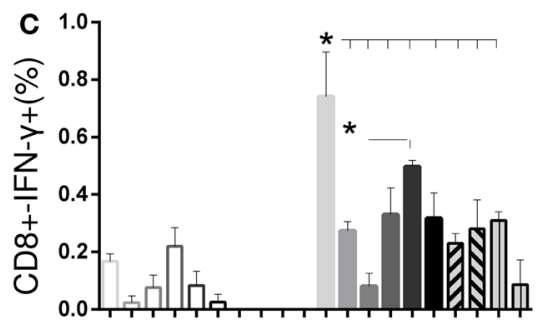

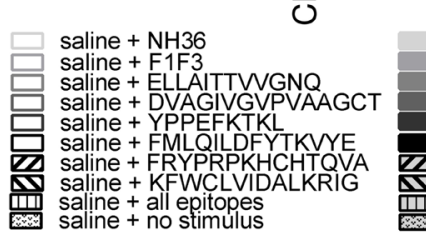
chimera $+\mathrm{NH} 36$ chimera + F1F chimera + ELLAITTWGNQ chimera + DVAGIVGVPVAAGCT chimera + YPPEFKTKL chimera + FMLQILDFYTKVYE chimera + FRYPRPKHCHTQVA
chimera + KFWCLVIDALKRIG chimera + all epitopes chimera + all epitopes

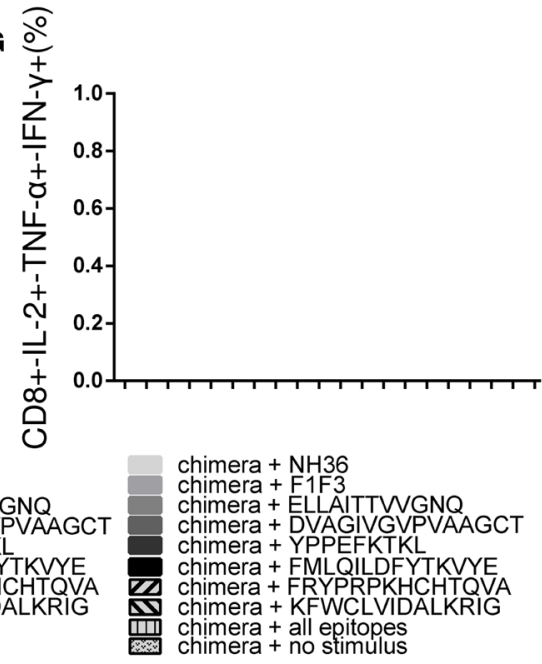

FIGURE 10 | Multiparameter cytometry analysis disclosed that the YPPEFKTKL followed by the DVAGIVGVPVAAGCT, FMLQILDFYTKVYE, and ELLAITTVVGNQ epitopes induced the most potent CD8+ T cell response. Splenocytes of chimera-vaccinated mice were incubated with NH36, the chimera, the ELLAITTWGNQ, DVAGIVGVPVAAGCT, YPPEKTKL, FMLQILDFYTKVYE, FRYPRPKHCCHTQVA, and KFWCLVIDALKRIG sequences, or with the mixture of all the epitopes, at week 11 after infection. The magnitude of the CD4+ T cell response was disclosed by the frequencies of the CD4+ lymphocytes expressing IL-2 (A), TNF- $\alpha$ (B), IFN- $\gamma$ (C), IL-2/TNF- $\alpha$ (D), TNF- $\alpha /$ IFN- $\gamma$ (E), IL-2/IFN- $\gamma$ TNF- $\alpha /$ IFN- $\gamma$ (F), and IL-2/TNF- $\alpha /$ IFN- $\gamma$ TNF- $\alpha /$ IFN- $\gamma$ (G) in response to each antigen. Bars represent means + SE of two independent experiments, each one with 8-10 animals per treatment. YPPEFKTKL was the most potent epitope. Alone, it induced higher proportions of CD8+ T cells secreting IFN- $\gamma$ and IFN- $\gamma$ in combination with IL-2 than the chimera; together with DVAGIVGVPAAGCT and KFWCLVIDALKRIG, the highest frequencies of CD8+-IL-2 T cells and combined only with DVAGIVGVPAAGCT, the highest proportions of CD8+-TNF- $\alpha$-IFN- $\gamma$ T cells. In addition, DVAGIVGVPAAGCT increased the frequencies of CD8+-TNF- $\alpha$-IL-2 T cells. In contrast, ELLAITTWGNQ and the FMLQILDFYTKVYE epitopes increased the frequencies of $T$ cells secreting only TNF- $\alpha$.

T cells of F3, FMLQILDFYTKVYE, FRYPRPKHCHTQVA, and KFWCLVIDALKRIG differ in only one amino acid (28).

Strong IgG1, IgG2a, and/or IgG2b anti-NH36 antibody responses were described after mice vaccination with the gene of NH36 $(23,24,27)$, with the NH36 recombinant protein in combination with saponin $(17,28,29), \mathrm{CPG}$ and polylactil glycolide particles (39), and the GLA-SE adjuvant (40), or with the NH36 cloned with a sterol 24-C-methyl transferase (NS), and used with GLA-SE adjuvant (30). Furthermore, higher IgG2/IgG1 antibody ratios were also found after immunotherapy of Leishmania infantum chagasi-infected dogs with NH36-DNA (25). Additionally, human vaccination with NS determined a preferential increase in IgG1 and IgG3 subclasses, which are dependent of Th1-like cytokines (30).

Vaccination with F3, but not with F1, induced higher IgG2a antibody levels than $\mathrm{NH} 36$, in mice challenged with L. chagasi (17). In contrast, IgG2a, IgG1 antibody levels were similar in mice challenged with L. amazonensis $(28,29)$. Although protection against leishmaniasis depends more, on the cellular than on the humoral immune response, it is worth to note that these increased antibody subtypes are strong surrogates predictive of protection (41), which indicate the decrease of parasite load $(17,28,29)$ and that could also be the basis of the development of a transmission blocking vaccine $(38,42)$.

We previously identified in the F3 domain, the epitopes AVQKRVKEVGTKPAAFML (202-219), VYEKERNTYATV (228-239), and FRYPRPKHCHTQVA (278-291), as the most relevant targets of the anti-NH36 antibody response in mice (17). Supporting our results, two B cell epitopes for dog and human antibodies were confirmed in the sequence of NH36 by other group (43). These epitopes, called peptide 17 and 18 (43), overlap with the sequences AVQKRVKEVGTKPAAFML and NQTLEKVTRNARLVADVAG that we previously described in the F3 and F1 domains, respectively (17). Interestingly, the peptide17 diagnosed with $100 \%$ sensitivity canine and human VL (43). These results disclose the universal nature of the B cell epitopes of NH36.

We further demonstrated that the admixed F1 + F3 vaccine induced more IgG, IgG1, and IgG2a antibodies than the F3 or the $\mathrm{F} 1$ vaccines did independently, suggesting a potentiated 
immunogenicity. However, the presentation of the domains cloned in tandem as the chimera was superior and exceeded the IgG and IgG2a response above the admixed domains showing an additional dose-response effect.

Our results demonstrate that the delivery of the F1 and F3 domains cloned in tandem, rather than as a simple mixture, increases the probabilities of a single antigen presenting cell to exhibit simultaneously both the CD8+ and CD4+ epitopes to lymphocytes, optimizing the immunogenicity. This might occur through cross-priming when MHC class II molecules can present both, exogenous molecules acquired by antigen presenting cells and endogenous degraded antigens $(44,45)$. Therefore, our results suggest that not only the composition of the epitopes and subunits is critical but also how the epitopes are exposed in the tridimensional structure of the vaccine antigen (46). In fact, only the tandem arrangement, but not the independent subunits containing an HIV epitope represented the most efficient immunogenic conformation (46). Another advantage of the presentation of the epitopes in a recombinant chimera is that it facilitates the scaling-up of the antigen, reducing the production yield time and cost, when large amounts of antigen for clinical phase III and IV assays are needed.

Regarding the generation of the cellular immune response, the F3 domain induced stronger IDR than the F1 protein in mice vaccinated against $L$. chagasi (17) and L. amazonensis $(28,29)$. In this investigation, we showed that the admixed antigens were even better than F3, but also, that the chimera induced the strongest IDR after infection and an increased a dose-response effect. Supporting our previous descriptions $(17,28,29)$, the IDR was an important correlate of protection that increased along with the decrease of parasite load, indicating the generation of a robust cellular immune response against L. amazonensis optimized by vaccination with the chimera.

We confirmed here our previous results showing that mice vaccinated with $\mathrm{F} 3$ and challenged with $L$. amazonensis increase the IFN- $\gamma$ and TNF- $\alpha$ secretion but have a null IL-10 response $(28,29)$. Mice vaccinated with the F1 domain, on the other hand, secreted IFN- $\gamma$, TNF- $\alpha$, and IL-10, suggesting the simultaneous stimulation of $\mathrm{T}$ reg subsets and the presence of epitopes for $\mathrm{T}$ regs along its sequence $(28,29)$. In this investigation, vaccination with the chimera induced a concomitant higher expression of IFN- $\gamma$ and IL-10 than the admixed domains, and a doseresponse effect. This is remarkable considering that IL-10 has been shown to be related both to the pathology and the control of CL (47) and that IFN- $\gamma$ has also a dual role, as inducer of effector mechanisms and, conversely, as a mediator of inflammation and pathogenesis (48). Increased CD4+ T cell proportions secreting IFN- $\gamma$ with low proportions of CD4+-IL- 4 T cells were also described in mice vaccinated with $\mathrm{NH} 36$ and challenged with L. mexicana (40).

We additionally demonstrated that the chimera vaccine at $100 \mu \mathrm{g} /$ dose induced the highest proportions of all types of CD4+ and CD8+ T cells secreting IL- 2 , TNF- $\alpha$, or IFN- $\gamma$ alone, TNF- $\alpha$ in combination with IL- 2 or IFN- $\gamma$, and the highest percentage of CD4+ multifunctional cells secreting IL-2, TNF- $\alpha$, and IFN- $\gamma$ simultaneously. In fact, the chimera optimized the induction of a CD4+ Th1 immune response by promoting the highest proportions of CD4+ effector and long-term memory potential $\mathrm{T}$ cells, being the strongest vaccine at all the steps of the CD4 $\mathrm{T}$ cell differentiation (36). Thus, and confirming the in silico prediction (17) important epitopes for CD4+ T cells are present both in the F1 and F3 domains and their presentation in tandem, in the chimera, improve significantly their immunogenicity. This very desirable performance was observed also for the cytotoxic immune response. The highest proportions of all subtypes of CD8+-cytokine secreting $\mathrm{T}$ cells were observed in response to the chimera, except for the multifunctional cells. As detected for the CD4+ T cells, F1 was the second most important vaccine for the induction of the cytotoxic response while no enhancement was induced by the admixed antigens.

The immunotherapeutic effect induced by the F1 or F3 domains against $L$. amazonensis infection was predicted by the frequencies of the CD4+ and CD8+ T cells producing IL- 2 or TNF- $\alpha$ or both (29). Total frequencies and frequencies of double-cytokine CD4 T cell producers were enhanced by $\mathrm{F} 1$ and $\mathrm{F} 3$ vaccines. In contrast to what described for prophylactic vaccination with the chimera, no increases in CD4+ multifunctional $\mathrm{T}$ cells were observed after immunotherapy with the independent domains (29). On the other, the F1 vaccine was codominant in prophylaxis with the chimera, for both CD4+ and CD8+ T cells (this investigation) and promoted the highest proportions of CD8+ multifunctional $\mathrm{T}$ cells when used for immunotherapy (29).

The reduction of parasite load and sizes of lesions confirmed the predictions of the immunological assays. Cross-protection to L. amazonensis infection was maximal (99.8-99.9\%) in mice vaccinated with the chimera. As described before, and in spite of raising a strong CD4+ and CD8+ T cell immunogenic response, the $\mathrm{F} 1$ vaccine was less protective $(17,28)$.

We concluded that the chimera optimized the immune crossprotection against L. amazonensis, above the levels induced by the F1 and F3 domains either admixed or independently. Our results indicated the development of a Th1-immune response mediated by CD4+ T cell epitopes of the F3 and F1 domains, a cytotoxic response induced by $\mathrm{F} 1$ and the potential presence of $\mathrm{T}$ reg epitopes in the $\mathrm{F} 1$ domain determining also a potential regulatory response. The three arms of immunity increased by the presentation of the F1 and F3 epitopes in tandem in the F1F3 chimera.

Progressing toward the definition of a polytope vaccine, we were further able to identify the epitopes of NH36 responsible for the cross-protection against L. amazonensis infection. Confirming that they are the target of the immune response, some epitopes exceeded the levels of cytokine secretion induced by the chimera (33). The FMLQILDFYTKVYE and YPPEFKTKL sequences promoted, respectively, a 3.2- and 3.8-fold enhance in IFN- $\gamma$, a 3.2- and 2.9-fold increase in IL-10, and a 2.3- and 1.5fold augment of TNF- $\alpha$ secretion above the levels generated by the chimera.

Additionally, we further elucidated that the main Th1 response induced by the NH36 and the chimera was due to the FRYPRPKHCHTQVA epitope of F3, which generated elevated IFN- $\gamma / \mathrm{IL}-10$ and TNF- $\alpha / \mathrm{IL}-10$ ratios and the highest proportions of CD4+-TNF- $\alpha,-$ TNF- $\alpha$-IL-2, -TNF- $\alpha-I F N-\gamma$, -IFN- $\gamma$-IL-2, and multifunctional IL-2-TNF- $\alpha-I F N-\gamma$ T cells. 
The FRYPRPKHCHTQVA epitope might be the reason for the CD4+ Th1 TNF- $\alpha$-mediated protection induced by F3 and previously detected against both visceral (17) and CL in mice [(this investigation) $(28,29)]$. In fact, only the FRYPRPKHCHTQVA sequence determined a high CD4+ response with strong IFN- $\gamma$, TNF- $\alpha$ secretion, and null IL-10 response, as already described for the $\mathrm{F} 3$ vaccine $(17,29)$.

Although first predicted as a CD8 epitope $(17,28)$, the YPPEFKTKL sequence of F1 also contributed to the CD4+ $\mathrm{T}$ cell response. In fact, it was the second most important CD4+-epitope, which stimulated a high IFN- $\gamma / \mathrm{IL}-10$ ratio and increased proportions of CD4+ T cells producing TNF- $\alpha$, IFN- $\gamma$, IL-2-IFN- $\gamma$, and TNF- $\alpha$-IFN- $\gamma$. Additionally, the YPPEFKTKL and DVAGIVGVPAAGCT epitopes were the most important sequences inducing the CD8+ $\mathrm{T}$ cell response. Likewise, the ELLAITTVVGNQ and the FMLQILDFYTKVYE epitopes also induced elevated frequencies of CD8-TNF- $\alpha$ T cells, although they were predicted as CD4+ T cell epitopes of mice $(17,28)$. In agreement with that, the AFMLQILDF sequence was also predicted as a human epitope of CD8+ T cells binding the HLA$\mathrm{A}^{\star} 2402$ and HLA-B ${ }^{\star} 4402$, HLA-A*01 molecules (49).

We demonstrated that the YPPEFKTKL epitope capabilities of stimulating both the CD4+ and CD8+ T cell response, with intense production of pro-inflammatory cytokines, indicating its potential PAN epitope nature (50). YPPEFKTKL was the only predicted epitope for CD8+ T cells identified in the F1 domain (17) and because of that, it is probably the responsible for the CD8- T cell mediate vaccine protection against $L$. amazonensis infection, attributed to the F1 vaccine (28). The enhancement of the IL-10 secretion induced by the F1 vaccine [(this investigation) $(28,29)]$ and YPPEFKTKL indicate that this sequence might also be a $\mathrm{T}$ regulatory epitope, which deserves better characterization. Supporting its universality and biological relevance, the YPPEFKTKL sequence was also predicted with high scores for the binding of the human Class I HLA-A ${ }^{\star} 2402$ and HLA-B ${ }^{\star} 0702$ molecules, induced the IFN- $\gamma$ secretion by $\mathrm{PBMC}$ of asymptomatic, IDR positive human individuals infected with $L$. infantum and was found to be highly conserved in the NH sequence of all the studied Leishmania species (49).

For its multiple capabilities, the YPPEFKTKL epitope might be considered as a Pan epitope candidate (51-53). In fact, the sequence MDEPTLLYV was described as a PANDR epitope of the A15 hexon protein of adenovirus (52) while the synthetic more preferably PADRE peptide composition is aKXVAAWTLKAAa (54). In order to constitute a PADRE epitope, the peptide should contain defined amino acids in R1, R2, R3, R4, and R5 (54). Remarkably, and as expected for a PADRE sequence (54), the YPPEFKTKL contains $\mathrm{Y}$ as the $\mathrm{R} 2$ residue, four residues in R3, where three to five amino acids are needed, and the sequences KT followed by TKL in R4, while the expected combinations for R4 are KT, TLK, or WTLK (54). The adenovirus epitope contains TLL instead of TLK in the place of R4 (52).

YPPEFKTKL of $L$. donovani maintains identical sequence in the NHs of L. infantum chagasi, L. infantum, L. amazonensis, L. major, and $L$. mexicana (49). TKL is substituted with TNL in $L$. tropica while the second residue of $\mathrm{R} 2, \mathrm{P}$, is substituted by $\mathrm{S}$ in the NHs of L. braziliensis and Leishmania panamensis, both of the subgenus Vianna (49).

Another common feature of the NH36 epitopes to PADRE sequences is found in the KFWCLVIDALKRIG CD4+ predicted epitope of F3, which shares with the aKFVAAWTLKAAa of the PADRE sequence the first KF residues (54). This epitope induced a mild secretion of IFN- $\gamma$, TNF- $\alpha$, and IL-10 and increased frequencies of CD4+ multifunctional T cells.

In spite the intense research on development of anti-Leishmania vaccines in animals models $(11,55)$ only a few of them are the basis of potential synthetic or epitope vaccines. The kmp-11 (56), the amastigote A2 (57), and the polytope vaccine containing LPG-3, LmSTI-1, CPB, and CPC (58) present epitopes for the CD8+ T cells. On the other hand, the LACK158-173 peptide (59), the amastigote A2 antigen (57), and the MML-triple fusion L. major vaccine expressed in adenovirus (37) determined a Th1biased CD4 T cell response.

In this investigation, we demonstrated that arrangement of the epitopes of the $\mathrm{NH}$ of $L$. donovani NH36 in tandem, in a chimera, improved the cross-protection to CL caused by L. amazonensis. We found that the chimera optimized the vaccine efficacy, probably by increasing the probabilities of cross-presentation as a strategy to enhance immunity $(44,45)$. We further advanced in the identification of the most relevant epitopes responsible for the immune responses generated by the subunit vaccines $(17,28,29)$. We found potent epitopes for the generation of the CD4+-Th1, cytotoxic and potential T regulatory response and recognized among them at least one with PADRE capabilities (54). The data gathered in our work will help in the development of a polytope vaccine against visceral and CL, which will allow to fight the disease with enhanced efficacy.

\section{AUTHOR CONTRIBUTIONS}

MA-S and DN conducted the experiments, MA-S, DN and AM acquired data, MA-S, DN, MP, and CP-d-S analyzed data. CP-d-S designed research studies. MA-S and CP-d-S prepared the figures. CP-d-S wrote the manuscript, and all authors have read and approved the final manuscript.

\section{ACKNOWLEDGMENTS}

MA-S was a recipient of an MSc fellowship from Coordenação de Aperfeiçoamento de Pessoal de Nível Superior (CAPES), Brazil.

\section{FUNDING}

This work was supported by Conselho Nacional de Desenvolvimento Científico e Tecnológico (CNPQ) fellowship 310977/2014-2 and grant 404400/2012-4 (to CP-d-S) and by Fundação Carlos Chagas Filho de Amparo à Pesquisa do Estado do Rio de Janeiro (FAPERJ) grants E-26-201.583/2014 and E-26/111.682/2013(toCP-d-S) andfellowshipsE-26/102415/2010 and E-26/201747/2015 (to DN). 


\section{SUPPLEMENTARY MATERIAL}

The Supplementary Material for this article can be found online at http://journal.frontiersin.org/article/10.3389/fimmu. 2017.00100/full\#supplementary-material.

FIGURE S1 Monomer of Leishmania donovani nucleoside hydrolase (NH36). (A) Illustration of the tridimensional structure of the $\mathrm{NH} 36$ monomer

\section{REFERENCES}

1. World Health Organization. WHO Report on Global Surveillance of Epidemic-Prone Infectious Diseases - Leishmaniasis. (2016). Available from: http://www.who.int/csr/resources/publications/CSR_ISR_2000_1leish/en/

2. Alvar J, Vélez ID, Bern C, Herrero M, Desjeux P, Cano J, et al. Leishmaniasis worldwide and global estimates of its incidence. PLoS One (2012) 7(5):e35671. doi:10.1371/journal.pone.0035671

3. Da-Cruz AM, Bittar R, Mattos M, Oliveira-Neto MP, Nogueira R, PinhoRibeiro V, et al. T-cell-mediated immune responses in patients with cutaneous or mucosal leishmaniasis: long-term evaluation after therapy. Clin Diagn Lab Immunol (2002) 9(2):251-6.

4. Silveira FT, Lainson R, Corbett CE. Clinical and immunopathological spectrum of American cutaneous leishmaniasis with special reference to the disease in Amazonian Brazil: a review. Mem Inst Oswaldo Cruz (2004) 99(3):239-51. doi:10.1590/S0074-02762004000300001

5. Silveira FT, Lainson R, De Castro Gomes CM, Laurenti MD, Corbett CE. Immunopathogenic competences of Leishmania (V.) braziliensis and L. (L.) amazonensis in American cutaneous leishmaniasis. Parasite Immunol (2009) 31(8):423-31. doi:10.1111/j.1365-3024.2009.01116.x

6. Mendes Wanderley JL, Costa JF, Borges VM, Barcinski M. Subversion of immunity by Leishmania amazonensis parasites: possible role of phosphatidylserine as a main regulator. J Parasitol Res (2012) 2012:981686. doi:10.1155/2012/981686

7. França-Costa J, Van Weyenbergh J, Boaventura VS, Luz NF, Malta-Santos H, Oliveira MC, et al. Arginase I, polyamine, and prostaglandin E2 pathways suppress the inflammatory response and contribute to diffuse cutaneous leishmaniasis. J Infect Dis (2015) 211(3):426-35. doi:10.1093/infdis/jiu455

8. Mayrink W, Botelho AC, Magalhães PA, Batista SM, de Lima AO, Genaro $\mathrm{O}$, et al. Immunotherapy, immunochemotherapy and chemotherapy for American cutaneous leishmaniasis treatment. Rev Soc Bras Med Trop (2006) 39(1):14-21. doi:10.1590/S0037-86822006000100003

9. Croft SL, Sundar S, Fairlamb AH. Drug resistance in leishmaniasis. Clin Microbiol Rev (2006) 19(1):111-26. doi:10.1128/CMR.19.1.111-126.2006

10. Perez-Franco JE, Cruz-Barrera ML, Robayo ML, Lopez MC, Daza CD, Bedoya A, et al. Clinical and parasitological features of patients with American cutaneous leishmaniasis that did not respond to treatment with meglumine antimoniate. PLoS Negl Trop Dis (2016) 10(5):e0004739. doi:10.1371/journal. pntd.0004739

11. Palatnik-de-Sousa CB. Vaccines for leishmaniasis in the fore coming 25 years. Review. Vaccine (2008) 26(14):1709-24. doi:10.1016/j.vaccine.2008. 01.023

12. Palatnik-de-Sousa CB, Silva-Antunes I, de Morgado AA, Menz I, Palatnik M, Lavor C. Decrease of the incidence of human and canine visceral leishmaniasis after dog vaccination with Leishmune in Brazilian endemic areas. Vaccine (2009) 27(27):3505-12. doi:10.1016/j.vaccine.2009.03.045

13. Regina-Silva S, Feres AM, França-Silva JC, Dias ES, Michalsky ÉM, de Andrade HM, et al. Field randomized trial to evaluate the efficacy of the Leish-Tec ${ }^{\circledast}$ vaccine against canine visceral leishmaniasis in an endemic area of Brazil. Vaccine (2016) 34(19):2233-9. doi:10.1016/j.vaccine. 2016.03.019

14. Starita C, Gavazza A, Lubas G. Hematological, biochemical, and serological findings in healthy canine blood donors after the administration of CaniLeish $^{\circledast}$ vaccine. Vet Med Int (2016) 2016:4601893. doi:10.1155/2016/ 4601893

15. Lukes J, Mauricio IL, Schönian G, Dujardin JC, Soteriadou K, Dedet JP, et al. Evolutionary and geographical history of the Leishmania donovani was obtained by homology modeling to the sequence of the $\mathrm{NH}$ of Leishmania major template (RCSB PDB code: 1EZR; crystal structure of $\mathrm{NH}$ of $L$. major) with the sequences of the $\mathrm{N}$-terminal ( $\mathrm{F} 1$, amino acids 1-103 in lime green), central (F2, amino acids 104-198 in gray), and C-terminal (F3, amino acids 199-314 in cyan) moieties, using the Modeller 9.10 software. (B) MHC class II-IAd and IEd, haplotype H2d CD4+ T cell epitopes (dark blue) and of MHC class I Ld-CD8+ $\mathrm{T}$ cell predicted epitopes (red) of the C-terminal and $\mathrm{N}$-terminal moieties. This illustration was modified from Nico et al. (29) and reproduced with authorization of the authors

complex with a revision of current taxonomy. Proc Natl Acad Sci U S A (2007) 104(22):9375-80. doi:10.1073/pnas.0703678104

16. Mauricio IL, Yeo M, Baghaei M, Doto D, Pratlong F, Zemanova E, et al. Towards multilocus sequence typing of the Leishmania donovani complex: resolving genotypes and haplotypes for five polymorphic metabolic enzymes (ASAT, GPI, NH1, NH2, PGD). Int J Parasitol (2006) 36(7):757-69. doi:10.1016/ j.ijpara.2006.03.006

17. Nico D, Claser C, Borja-Cabrera GP, Travassos LR, Palatnik M, Soares IS, et al. Adaptive immunity against Leishmania nucleoside hydrolase maps its c-terminal domain as the target of the $\mathrm{CD} 4+\mathrm{T}$ cell-driven protective response. PLoS Negl Trop Dis (2010) 4(11):e866. doi:10.1371/journal. pntd.0000866

18. da Silva VO, Borja-Cabrera GP, Correia Pontes NN, de Souza EP, Luz KG, Palatnik M, et al. A phase III trial of efficacy of the FML-vaccine against canine kala-azar in an endemic area of Brazil (São Gonçalo do Amaranto, RN). Vaccine (2000) 19(9-10):1082-92. doi:10.1016/S0264-410X(00)00339-X

19. Borja-Cabrera GP, Correia Pontes NN, da Silva VO, Paraguai de Souza E, Santos WR, Gomes EM, et al. Long lasting protection against canine kalaazar using the FML-QuilA saponin vaccine in an endemic area of Brazil (São Gonçalo do Amarante, RN). Vaccine (2002) 20(27-28):3277-84. doi:10.1016/ S0264-410X(02)00294-3

20. Iovane E, Giabbai B, Muzzolini L, Matafora V, Fornili A, Minici C, et al. Structural basis for substrate specificity in group I nucleoside hydrolases. Biochemistry (2008) 47(15):4418-26. doi:10.1021/bi702448s

21. Versées W, Goeminne A, Berg M, Vandemeulebroucke A, Haemers A, Augustyn K, et al. Crystal structures of T. vivax nucleoside hydrolase in complex with new potent and specific inhibitors. Biochim Biophys Acta (2009) 1794(6):953-60. doi:10.1016/j.bbapap.2009.02.011

22. Paraguai de Souza E, Bernardo RR, Palatnik M, Palatnik de Sousa CB Vaccination of Balb/c mice against experimental visceral leishmaniasis with the GP36 glycoprotein antigen of Leishmania donovani. Vaccine (2001) 19(23-24):3104-15. doi:10.1016/S0264-410X(01)00031-7

23. Aguilar-Be I, Zardo RS, Paraguai de Souza E, Borja-Cabrera GP, RosadoVallado M, Mut-Martin M, et al. Cross-protective efficacy of a prophylactic Leishmania donovani DNA vaccine against visceral and cutaneous murine leishmaniasis. Infect Immun (2005) 73(2):812-9. doi:10.1128/IAI.73.2.812819.2005

24. Gamboa-León R, Paraguai de Souza E, Borja Cabrera GP, Santos FN, Miyashiro LM, Pinheiro RO, et al. Immunotherapy against visceral leishmaniasis with the nucleoside hydrolase-DNA vaccine of $L$. donovani. Vaccine (2007) 24(22):4863-73. doi:10.1016/j.vaccine.2006.03.005

25. Borja-Cabrera GP, Santos FB, Picillo E, Gravino E, Manna L, Palatnik de Sousa CB. Nucleoside hydrolase DNA vaccine against canine visceral leishmaniasis. Proc Vaccinol (2009) 1(1):104-9. doi:10.1016/j.provac.2009.07.019

26. Al-Wabel MA, Tonui WK, Cui L, Martin SK, Titus RG. Protection of susceptible $\mathrm{BALB} / \mathrm{c}$ mice from challenge with Leishmania major by nucleoside hydrolase, a soluble exo-antigen of Leishmania. Am J Trop Med Hyg (2007) 77(6):1060-5.

27. Souza LOP, Palatnik de Sousa CB. The nucleoside hydrolase DNA vaccine VR1012NH36 in prophylactic vaccination against mice tegumentar leishmaniasis. Proc Vaccinol (2009) 1(1):120-3. doi:10.1016/j.provac.2009.07.022

28. Nico D, Gomes DC, Alves-Silva MV, Freitas EO, Morrot A, Bahia D, et al. Cross-protective immunity to Leishmania amazonensis is mediated by CD4+ and CD8+ epitopes of Leishmania donovani nucleoside hydrolase terminal domains. Front Immunol (2014) 5:189. doi:10.3389/fimmu.2014.00189

29. Nico D, Gomes DC, Palatnik-de-Sousa I, Morrot A, Palatnik M, Palatnikde-Sousa CB. Leishmania donovani nucleoside hydrolase terminal domains 
in cross-protective immunotherapy against Leishmania amazonensis murine infection. Front Immunol (2014) 5:273. doi:10.3389/fimmu.2014.00273

30. Coler RN, Duthie MS, Hofmeyer KA, Guderian J, Jayashankar L, Vergara J, et al. From mouse to man: safety, immunogenicity and efficacy of a candidate leishmaniasis vaccine LEISH-F3+GLA-SE. Clin Transl Immunol (2015) 4:e35. doi:10.1038/cti.2015.6

31. Cui L, Rajasekariah GR, Martin SK. A nonspecific nucleoside hydrolase from Leishmania donovani: implications for purine salvage by the parasite. Gene (2001) 280(1-2):153-62. doi:10.1016/S0378-1119(01)00768-5

32. NIH. Blast-Basic Local Alignment Search Tool. National Institute of Health (NIH) (2016). Available from: http://blast.ncbi.nlm.nih.gov/Blast.cgi

33. Kao DJ, Hodges RS. Advantages of a synthetic peptide immunogen over a protein immunogen in the development of an anti-pilus vaccine for Pseudomonas aeruginosa. Chem Biol Drug Res (2009) 74:33-42. doi:10.1111/ j.1747-0285.2009.00825

34. Seyed N, Taheri T, Rafati S. Post-genomics and vaccine improvement for Leishmania. Front Microbiol (2016) 7:467. doi:10.3389/fmicb.2016.00467

35. De Groot AS, Sbai H, Aubin CS, McMurry J, Martin W. Immuno-informatics: mining genomes for vaccine components. Immunol Cell Biol (2002) 80(3):255-69. doi:10.1046/j.1440-1711.2002.01092.x

36. Seder RA, Darrah PA, Roederer M. T cell quality in memory and protection: implications for vaccine design. Nat Rev (2008) 8(4):247-58. doi:10.1038/ nri2274

37. Darrah PA, Patel DT, De Luca PM, Lindsay RWB, Davey DF, Flynn BG, et al. Multifunctional $\mathrm{T}_{\mathrm{H}} 1$ cells define a correlate of vaccine-mediated protection against Leishmania major. Nat Med (2007) 13(7):843-50. doi:10.1038/nm1592

38. Palatnik de Sousa CB, de Barbosa AF, Oliveira SM, Nico D, Bernardo RR, Santos WR, et al. FML vaccine against canine visceral leishmaniasis: from second-generation to synthetic vaccine. Expert Rev Vaccines (2008) 7(6):833-51. doi:10.1586/14760584.7.6.833

39. Hudspeth EM, Wang Q, Seid CA, Hammond M, Wei J, Liu Z, et al. Expression and purification of an engineered, yeast-expressed Leishmania donovani nucleoside hydrolase with immunogenic properties. Hum Vaccin Immunother (2016) 12(7):1707-20. doi:10.1080/21645515.2016.1139254

40. McAtee CP, Seid CA, Hammond M, Hudspeth E, Keegan BP, Liu Z, et al. Expression, purification, immunogenicity and protective efficacy of a recombinant nucleoside hydrolase from Leishmania donovani, a vaccine candidate for preventing cutaneous leishmaniasis. Protein Expr Purif (2016) 130:129-36. doi:10.1016/j.pep.2016.10.008

41. Plotkin SA. Vaccines: correlates of vaccine-induced immunity. Clin Infect Dis (2008) 47(3):401-9. doi:10.1086/589862

42. Saraiva EM, de Figueiredo Barbosa A, Santos FN, Borja-Cabrera GP, Nico D, Souza LO, et al. The FML-vaccine (Leishmune) against canine visceral leishmaniasis: a transmission blocking vaccine. Vaccine (2006) 24(13):2423-31. doi:10.1016/j.vaccine.2005.11.061

43. Costa MM, Penido M, dos Santos MS, Doro D, de Freitas E, Michalik MS, et al. Improved canine and human visceral leishmaniasis immunodiagnosis using combinations of synthetic peptides in enzyme-linked immunosorbent assay. PLoS Negl Trop Dis (2012) 6(5):e1622. doi:10.1371/ journal.pntd.0001622

44. Leung CS. Endogenous antigen presentation of MHC class II epitopes through non-autophagic pathways. Front Immunol (2015) 6:464. doi:10.3389/ fimmu. 2015.00464

45. Chow KV, Sutherland RM, Zhan Y, Lew AM. Heterogeneity, functional specialization and differentiation of monocyte-derived dendritic cells. Immunol Cell Biol (2016). doi:10.1038/icb.2016.104

46. Sun Z, Zhu Y, Wang Q, Ye L, Dai Y, Su S, et al. An immunogen containing four tandem 10E8 epitope repeats with exposed key residues induces antibodies that neutralize HIV-1 and activates an ADCC reporter gene. Emerg Microbes Infect (2016) 5:e65. doi:10.1038/emi.2016.86

47. Ji J, Masterson J, Sun J, Soong L. CD4 CD25 regulatory T cells restrain pathogenic responses during Leishmania amazonensis infection. J Immunol (2005) 174(11):7147-53. doi:10.4049/jimmunol.174.11.7147
48. Carneiro MB, Lopes ME, Vaz LG, Sousa LM, dos Santos LM, de Souza $\mathrm{CC}$, et al. IFN- $\gamma$-dependent recruitment of $\mathrm{CD} 4(+) \mathrm{T}$ cells and macrophages contributes to pathogenesis during Leishmania amazonensis infection. J Interferon Cytokine Res (2015) 35(12):935-47. doi:10.1089/jir. 2015.0043

49. Santos ML, Nico D, Oliveira FA, Barreto AS, De Sousa IP, Carrillo E, et al. Leishmania donovani-nucleoside hydrolase (NH36) domains induce T-cell cytokine responses in human visceral leishmaniasis. Front Immunol (2017) 8:227. doi:10.3389/fimmu.2017.00227

50. Haveman LM, Bierings M, Legger E, Klein MR, de Jager W, Otten HG, et al. Novel pan-DR-binding $\mathrm{T}$ cell epitopes of adenovirus induce proinflammatory cytokines and chemokines in healthy donors. Int Immunol (2006) 18(11):1521-9. doi:10.1093/intimm/dxl085

51. Alexander J, Sidney J, Southwood S, Ruppert J, Oseroff C, Maewal A, et al. Development of high potency universal DR-restricted helper epitopes by modification of high affinity DR-blocking peptides. Immunity (1994) 1(9):751-61. doi:10.1016/S1074-7613(94)80017-0

52. Ghaffari-Nazari H, Tavakkol-Afshari J, Jaafari MR, Tahaghoghi-Hajghorbani S, Masoumi E, Jalali SA. Improving multi-epitope long peptide vaccine potency by using a strategy that enhances CD4+ T help in BALB/c mice. PLoS One (2015) 10(11):e0142563. doi:10.1371/journal.pone.0142563

53. El Bissati K, Chentoufi AA, Krishack PA, Zhou Y, Woods S, Dubey JP, et al. Adjuvanted multi-epitope vaccines protect HLA-A $A^{\star} 11: 01$ transgenic mice against Toxoplasma gondii. JCI Insight (2016) 1(15):e85955. doi:10.1172/jci. insight. 85955

54. Alexander JL, Defrees S, Sette A. Induction of Immune Response against Desired Determinants. US patent No WO 1997026784 A1 (1997).

55. Kaye PM, Aebischer T. Visceral leishmaniasis: immunology and prospects for a vaccine. Clin Microbiol Infect (2011) 17(10):1462-70. doi:10.1111/j.1469-0691.2011.03610.x

56. Basu R, Roy S, Walden P. HLA class I-restricted $\mathrm{T}$ cell epitopes of the kinetoplastid membrane protein-11 presented by Leishmania donovani-infected human macrophages. J Infect Dis (2007) 195(9):1373-80. doi:10.1086/ 513439

57. Fernandes AP, Coelho EA, Machado-Coelho GL, Grimaldi G Jr, Gazzinelli RT. Making an anti-amastigote vaccine for visceral leishmaniasis: rational, update and perspectives. Curr Opin Microbiol (2012) 15(4):476-85. doi:10.1016/ j.mib.2012.05.002

58. Seyed N, Taheri T, Vauchy C, Dosset M, Godet Y, Eslamifar A, et al. Immunogenicity evaluation of a rationally designed polytope construct encoding HLA-A*0201 restricted epitopes derived from Leishmania major related proteins in HLA-A2/DR1 transgenic mice: steps toward polytope vaccine. PLoS One (2014) 9(10):e108848. doi:10.1371/journal. pone. 0108848

59. Kedzierska K, Curtis JM, Valkenburg SA, Hatton LA, Kiu H, Doherty PC, et al. Induction of protective $\mathrm{CD} 4+\mathrm{T}$ cell-mediated immunity by a Leishmania peptide delivered in recombinant influenza viruses. PLoS One (2012) 7(3):e33161. doi:10.1371/journal.pone.0033161

Conflict of Interest Statement: DN, MP, and CP-d-S are inventors of the patent file PI1015788-3 (INPI Brazil). MA-S and AM declares no conflict of interest.

The reviewer LFL declared a shared affiliation, though no other collaboration, with the authors to the handling Editor, who ensured that the process nevertheless met the standards of a fair and objective review.

Copyright $\odot 2017$ Alves-Silva, Nico, Morrot, Palatnik and Palatnik-de-Sousa. This is an open-access article distributed under the terms of the Creative Commons Attribution License (CC BY). The use, distribution or reproduction in other forums is permitted, provided the original author(s) or licensor are credited and that the original publication in this journal is cited, in accordance with accepted academic practice. No use, distribution or reproduction is permitted which does not comply with these terms. 